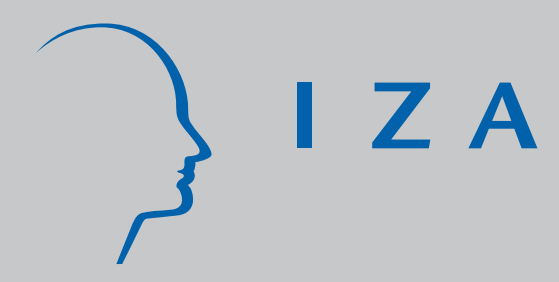

IZA DP No. 2357

Is there a Causal Effect of High School Math on Labor Market Outcomes?

Juanna Schrøter Joensen

Helena Skyt Nielsen

October 2006 


\title{
Is there a Causal Effect of High School Math on Labor Market Outcomes?
}

\author{
Juanna Schrøter Joensen \\ University of Aarhus \\ Helena Skyt Nielsen \\ University of Aarhus \\ and IZA Bonn
}

\section{Discussion Paper No. 2357 \\ October 2006}

\author{
IZA \\ P.O. Box 7240 \\ 53072 Bonn \\ Germany \\ Phone: +49-228-3894-0 \\ Fax: +49-228-3894-180 \\ E-mail: iza@iza.org
}

\begin{abstract}
Any opinions expressed here are those of the author(s) and not those of the institute. Research disseminated by IZA may include views on policy, but the institute itself takes no institutional policy positions.

The Institute for the Study of Labor (IZA) in Bonn is a local and virtual international research center and a place of communication between science, politics and business. IZA is an independent nonprofit company supported by Deutsche Post World Net. The center is associated with the University of Bonn and offers a stimulating research environment through its research networks, research support, and visitors and doctoral programs. IZA engages in (i) original and internationally competitive research in all fields of labor economics, (ii) development of policy concepts, and (iii) dissemination of research results and concepts to the interested public.
\end{abstract}

IZA Discussion Papers often represent preliminary work and are circulated to encourage discussion. Citation of such a paper should account for its provisional character. A revised version may be available directly from the author. 


\section{ABSTRACT}

\section{Is there a Causal Effect of High School Math on Labor Market Outcomes?*}

Outsourcing of jobs to low-wage countries has increased the focus on the accumulation of skills - such as Math skills - in high-wage countries. In this paper, we exploit a high school pilot scheme to identify the causal effect of advanced high school Math on labor market outcomes. The pilot scheme reduced the costs of choosing advanced Math because it allowed for at more flexible combination of Math with other courses. We find clear evidence of a causal relationship between Math and earnings for the students who are induced to choose Math after being exposed to the pilot scheme. The effect partly stems from the fact that these students end up with higher education.

JEL Classification: $\quad 120, \mathrm{~J} 24$

Keywords: Math, high school curriculum, instrumental variable, local average treatment effect

Corresponding author:

Helena Skyt Nielsen

Department of Economics

University of Aarhus

Bartholins Allé 4, Bld. 322

DK-8000 Aarhus C

Denmark

E-mail: HNielsen@econ.au.dk

\footnotetext{
Financial support from the Danish Research Agency is gratefully acknowledged. We appreciate useful comments from Joshua Angrist, Sandra Black, Nabanita Datta Gupta, Marianne Simonsen, Lars Skipper, Michael Svarer, Christopher Taber, as well as from discussants and participants at the DGPE, CEPR/IFAU/Uppsala University, CEPR/EENEE/University of Padova, and "Do Schools Matter?" Aarhus School of Business workshops, the SMYE 2006 and ESPE 2006 conferences, and we would like to thank seminar participants at $U$ of Texas, $U$ of Aarhus, Umeå University for comments on earlier drafts. The usual disclaimer applies.
} 


\section{Introduction}

Increased global competition and outsourcing of jobs to low wage countries have placed increased focus on the efficiency of the education system and the accumulation of skills. As a result, there is much public discussion about the optimal curriculum in many countries around the world. We devote this paper to study the effect of Math, which is one of the core elements of all curricula in primary and secondary schools.

It is well established that individuals with advanced Math qualifications perform better on a range of important economic performance measures. High school graduates with advanced Math qualifications have higher test scores, they attain a higher education and they earn a higher income than others. ${ }^{1}$ The question is, however, to what extent these observations indicate a causal impact of Math on performance, and to what extent it is a selection effect indicating that people with other favorable characteristics choose to acquire higher Math qualifications.

This question is closely related to the discussion of the human capital theory of education versus the signaling theory of education. According to the human capital theory, the Math premium indicates that more valuable skills are acquired during Math courses than during other coursework. Skills like clarity in expressions, logical reasoning and inference are acquired and added to the stock of human capital and subsequently make the advanced Math students more productive. On the other hand, drawing on the signaling theory, advanced Math works as a signal which is cheaper to acquire for individuals with favorable skills, such as higher aptitude or motivation. Accordingly, it implies that the seemingly high return to advanced Math courses is the result of self-selection of high ability individuals into advanced Math courses rather than enhanced productivity. ${ }^{2}$ Hence, a causal impact of Math would tend to confirm the human capital explanation, whereas a rejection of the causal impact would support the signaling explanation.

As a basis for policy discussion about changing high school curricula, we need hard evidence of the existence of a causal impact of Math courses on labor market success. Policy recommendations are distinctly different depending on the conclusion. If we cannot reject a causal impact of Math on outcomes relative to other subjects, it implies that policy makers should consider enhanced weight on Math in high school curricula for all students. On the other hand, a rejection of the causal effect also rejects the need for an enhanced Math curriculum since it may lead to a potentially inefficient allocation of students and workers after high school.

In order to estimate the causal effect of Math on earnings, the seminal paper by Altonji (1995) and its successors apply the curriculum of the average student from the relevant high school as an instrument for acquired Math qualifications. This instrument, however, is potentially invalid because the instrument is likely

\footnotetext{
${ }^{1}$ See e.g. Altonji (1995), Levine and Zimmerman (1995), Zangenberg and Zeuthen (1997), or Rose and Betts (2004).

${ }^{2}$ See e.g. Rose and Betts (2004) for a related discussion.
} 
to be correlated with unobservables reflecting earnings. Instead, we suggest to use instruments based on a Danish high school pilot scheme.

We use information about the population of high school students from cohorts 1986-87 which is available in a brand new register-based data set. We have information about detailed educational event histories and about the individual labor market histories, including actual labor market experience, unemployment degree and income. The data set is augmented with information about parents, courses taken in high school and high school grade point average (GPA). Furthermore, information about the distance from the individual's place of residence to nearby high schools has been added. The dataset has been gathered for the particular purpose of this study.

We use instruments that apply information about the pilot scheme introduced prior to the comprehensive structural high school reform of 1988. The pilot scheme was implemented as an experimental curriculum at some high schools prior to the reform. It allowed for a more flexible combination of advanced Math with other high school courses, which meant that $60 \%$ more students among those exposed to the pilot scheme chose advanced Math. The exogenous difference in flexibility allows us to create two instruments: PilotSchool (an indicator for whether the individual was enrolled at a pilot school or not) and DistPilotSchool (extra travel distance needed to reach a pilot school). Instrumental variable estimates identify the effect of Math on earnings for the group of students who were induced to choose advanced Math because they were able to combine advanced Math courses with a more flexible choice of additional advanced courses, which was not possible without the pilot scheme. Without the pilot scheme, advanced Math was only supplied in a package with advanced Physics, which scared away a lot of potentially Math interested students. Some high schools got an exemption and were allowed to try out a pilot scheme where advanced Math could be combined with Chemistry. The idea that restrictive course packages consisting of advanced Math and another advanced Science course scared away potentially Math interested students is consistent with Albæk (2003).

Our empirical investigation of the effect of high school Math on labor market outcomes confirms the findings of Rose and Betts (2004) that Math matters. In accordance with their study, we find that students who choose the advanced Math course earn roughly $30 \%$ more than others. This earnings premium reflects a causal impact of Math on earnings for some subgroups of the population. Employing the instruments that are based on the pilot scheme, PilotSchool and DistPilotSchool, we find that the causal effect of high level Math is significantly positive. This means that individuals who are induced to choose advanced Math because they are allowed to combine advanced Math with advanced Chemistry instead of Physics earn more than they would have earned had they not chosen the combination of advanced Math and Chemistry.

The remainder of the paper is structured as follows: Section 2 surveys previous literature. Section 3 presents the high school structure and the pilot scheme which is central to the identification strategy of this paper. Section 4 presents the empirical methodology used to identify and estimate the causal impact of 
Math on labor market outcomes. Section 5 describes the data. Section 6 shows the results, and section 7 concludes the paper.

\section{Previous studies}

A causal effect of Math on earnings may work through several channels: enhanced cognitive or non-cognitive skills, changed preferences for education or enhanced productivity in completing a higher education. Arcidiacono (2004) finds that individuals with high math ability receive higher earnings regradless of their educational choices. And furthermore, he finds that they prefer both the subjects and the jobs associated with the lucrative majors.

In case there is an effect of Math courses on cognitive skills, the literature on the labor market returns to cognitive skills is informative for our study. Some of the skills learned in the high level Math course like clarity in expressions, logical reasoning and inference, as well as imagination and ingenuity will add to the general stock of cognitive skills which will prove powerful in any career in any field. Alexander and Pallas (1984) find that students who attended more Math courses in high school gained more knowledge and cognitive skills. Furthermore, consistent positive effects are found of general cognitive skills on employment, wages and earnings. ${ }^{3}$ High school graduates with high cognitive skills tend to get more secure jobs, even if they do not obtain higher earnings in the early career. The earnings gain seem to show up later in the career. Murnane, Willet \& Levy (1995) provide similar results for the effects of math skills on wages in addition to evidence of increasing importance of math skills in the labor market.

Cross-country studies also investigate the impact of Math on economic performance. Hanushek and Kimko (2000) was the first study to be concerned with the potential influence of the quality of education as measured by comparative Math and Science test scores on growth. They found a consistent, strong and stable effect of quality measures on growth. In fact, they found that one standard deviation increase leads to an increase in annual growth rates of more than one percentage points, which only makes sense if there are strong externalities related to accumulating high quality human capital. Lee and Barro (2001) extend the same data set and investigate the opposite relationship, namely the effect of growth on test scores. They find a positive effect of growth on reading test scores, but no effect on Math test scores. Hence, the cross-country studies indicate that there is a positive causal effect of high quality Math skills on economic growth.

A number of papers have studied the effect of high school curriculum on postsecondary schooling and earnings. Altonji (1995) pioneered this area of research. In a study based on the National Longitudinal Study of the High School Class of 1972 (NLS72), he uses the variation in curricula across US high schools to identify the effects of coursework on wages and educational outcomes. He finds a negligible effect of specific coursework, including Math. Levine and

\footnotetext{
${ }^{3}$ See e.g. Willis and Rosen (1979), Blackburn and Neumark (1993) and Cameron and Heckman (1993).
} 
Zimmerman (1995) find slightly stronger effects while comparing the results of analyses based on the National Longitudinal Study of Youth (NLSY) with analyses of the 1980 cohort from High School and Beyond (HSB). However, still any potential effects are restricted to certain subgroups (low educated men and highly educated women), which raises doubt about the existence of a causal impact of coursework on labor market outcomes. ${ }^{4}$

Rose and Betts (2004) use data for the 1982-cohort from HSB. This is an immense improvement upon the earlier studies for several reasons. First of all, the transcript data for the sampled individuals are more detailed than those used in the earlier papers. Secondly, the individuals are observed in their thirties rather than in their twenties, and finally, the individuals are observed after the huge increase in the college premium around 1990. Rose and Betts (2004) find that Math matters. Consistent with this result, Ackerman (2000) finds a $6 \%$ earnings increase per additional year of Math classes. Two-thirds of this effect is a direct effect, whereas one-third is an indirect effect running through the increased probability of college attendance.

Corroborative evidence is also provided by Perna and Titus (2004), who investigate the impact of state public policies on the type of institutions that high school graduates attend after graduation. Due to state public policies, only $27 \%$ of high school students in Alabama take upper-level Math courses compared to $61 \%$ in Nebraska. After investigating the relationship between Math coursework and college attendance, they find that academic preparation, as measured by Math coursework, is the strongest student-level predictor of college enrollment.

Our study contributes to the literature by using new and better instruments for acquired Math qualifications. Following Altonji (1995), previous studies have used the curriculum of the average student from the relevant high school as an instrument for acquired Math qualifications. However, as they point out, this experiment is not a clean natural experiment because the curriculum of the average individual at a given high school may be correlated with the average family background, primary school preparation, ability of the student body, and the quality of the courses. However, the authors try to come across this problem by signing the potential bias. Altonji (1995) concludes that the potential bias is positive, which means that the small effect of specific coursework that he finds may be interpreted as an upper bound. Furthermore, they try to control for high school specific effects by observed variables and by inclusion of high school fixed effects (FE). Instead, we suggest to use instruments based on a pilot scheme implemented for the cohorts starting in the Danish high school before the structural reform of 1988 .

\footnotetext{
${ }^{4}$ The fact that the returns cannot be attributed to specific courses is not necessarily a rejection of the human capital theory. Other skills than those related to specific coursework could be acquired. Bowles, Gintis and Osborne (2001) hypothesize that the most important human capital outcomes of high school are not related to the coursework as such, but rather to behavioral outcomes. They claim that high school teaches students non-cognitive skills such as punctuality, tactfulness and consistency, which are as important in the labor market as academic skills.
} 


\section{Math in the pre-1988 High School}

From 1961 through 2005, the main distinction in the Danish high school ${ }^{5}$ has been between an education founded in Mathematics ('Math track') or in language studies ('language track'). Our focus is on the 'branch-based' high school regime that existed from 1961 to 1988, where courses were grouped in restrictive course packages. There are two reasons why we focus on this period: First of all, the restrictive course packages provide us with exogenous variation in the cost of acquiring advanced Math qualifications. Secondly, the focus on individuals attending high school in the pre-1988 regime means that our data set includes labour market outcomes of the individuals while they are in their thirties.

The pre-1988 regime implied that the students at high school graduation had obtained one of the three Math levels available: high, medium or low level. The objective of the high and medium level Math courses, which were available for the Math track students was: "to teach them a number of mathematical concepts and ways of thinking, to prompt their sense of clarity in expressions and logical inference in proofs, to enhance their imagination and ingenuity, to let them practice handling case studies (including execution of numerical arithmetics), and to make them familiarized with applications of Mathematics within other fields." 6 The objective of the low level Math course for the language track students was partly to give them the impression of the mathematical methods and partly to give them some mathematical tools that could be useful to them later.

In Figure 1, we summarize the contents of the three types of Math courses available. The main difference between the high level and the medium level Math is that Geometry (core subjects (5) and (6)) is not taught at the medium level course. Furthermore, some subjects were to be treated differently when taught at the medium level course compared to the high level course. In the low level Math course, the content is reduced to Elementary Functions, Combinatorics and Probability Theory and Infinitesimal Calculus. ${ }^{7}$

In the empirical analysis, we distinguish between whether individuals take the high level Math course or not, meaning that we lump the medium and low level courses together in order to get a binary indicator. In addition to the number of lessons, the main difference between the high level and the medium level Math course is primarily Geometry. According to Rose and Betts (2004), Geometry is the mathematical topic that has that largest positive effect on future earnings. Hence, if there is a causal effect of Math, we expect it to show up in this set-up.

The high school attended by the pre-1988 cohorts was structured as follows: Upon entry, the students choose between the Math track and the language

\footnotetext{
${ }^{5}$ When we refer to the Danish high school, we mean the ordinary high school ('gymnasium'), which is the traditional academic track. There also exist high schools supplying technicaland business tracks along with other high school equivalent educations to prepare students for further studies. About $60 \%$ of the high school students from the relevant cohorts attend the ordinary high school.

${ }^{6}$ Quotation from the high school mission statement, see Petersen and Vagner (2003).

${ }^{7}$ See Petersen and Vagner (2003) for further details on the Math curricula.
} 
track. After the first year, they choose one of the eight branches that are summarized in Figure 2: SocSci-languages, Music-languages, modern languages, classical languages, Math-SocSci, Math-NatSci, Math-Music or Math-Physics. Students enrolled at a school which had implemented the pilot scheme also had the option to choose the Math-Chemistry branch. Math track students could choose between the last four (or five, if they were at a pilot school) course packages, and the students on the language track could choose between the first four branches. The bundling of courses made it possible both to specialize and to strengthen the potential synergies between related courses by doing crosscurricular work.

As is evident from Figure 2, the only way to obtain the high level Math course was to opt for the Math-Physics branch, unless you were enrolled at one of the pilot schools supplying the Math-Chemistry branch. The extended course flexibility at the pilot schools gives the students an increased incentive to choose high level Math since the students are not necessarily compelled to choose high level Physics, which is considered tough. Albæk (2003) also backs up this conclusion by a simple theoretical model, where he analyses the effect of restricted course packages on the choice of high school courses in a framework where the student maximizes his or her future entry probability at universities which is assumed to depend on GPA. This approach is consistent with the Danish post-secondary schooling system that screens students on GPA and high school course choices. Figure 3 indeed confirms that more students choose advanced Math at the pilot schools.

\section{Identification and Estimation of the Causal Effect of Math}

We identify the causal effect of high level Math by exploiting the exogenous cost variation that is obtained from the pilot scheme. In this section, we briefly describe the identification strategy and the IV estimation method.

Let $M a t h A_{i}$ be an indicator for whether individual $i$ chooses the high level Math course or not. There are counterfactual outcomes associated with the two possible Math level choices. Let $Y_{i 1}$ denote the outcomes of individual $i$ after high school if attending the high level Math course, $\operatorname{Math} A_{i}=1$, and $Y_{i 0}$ denote the outcomes if not, $M a t h A_{i}=0$. Hence, the causal effect of attending the high level Math course on subsequent outcomes is given by $Y_{i 1}-Y_{i 0}$. Since we observe only one of these for each individual, we need to impose assumptions in order to identify the treatment effects of attending the high level Math course.

In our main analysis, $Y_{i}$ denotes $\log$ earnings of individual $i$, and we estimate the following log earnings equation:

$$
Y_{i}=\beta_{0}+\beta_{1} X_{i}+\delta M a t h A_{i}+\varepsilon_{i},
$$

where $X_{i}$ is a vector of individual and family background characteristics of individual $i$. We will be more precise regarding the included control variables in Subsection 4.3. 
We assume that individuals choose high level Math if the expected gains exceed the expected costs of the investment, i.e. if $Y_{i 1}-Y_{i 0}-C_{i} \geq 0$. The costs of attending the high level Math course may also include effort and psychological costs. We parameterize the latent index assignment mechanism to obtain the selection equation:

$$
\text { Math } A_{i}=\mathbf{1}\left[\alpha_{0}+\alpha_{1} X_{i}+\theta Z_{i}+u_{i}>0\right],
$$

where $Z_{i}$ is an instrumental variable that affects the costs of choosing high level Math, but does not affect future circumstances through other channels than the likelihood of choosing high level Math.

The indicator variable for whether individual $i$ chose the high level Math course in high school, $M a t h A_{i}$, is potentially endogenous since there most likely exist unobserved variables affecting both earnings and the choice of high level Math. Hence, endogeneity bias could arise due to individuals self-selecting into Math courses based on expected earnings gains (selection on outcomes), or due to unobserved ability bias (selection on unobservables). Firstly, the choice of high level Math may be endogenous in the earnings equation if individuals, who aspire to go into a high-paying occupation, e.g. as Engineers, choose the high level Math course in order to enhance their possibilities to succeed as Engineers. ${ }^{8}$ Secondly, unobserved ability bias arises if Math level depends on unobserved ability. If only the most talented individuals choose to attend the high level Math course, and we fail to control for talent, then the estimate of $\delta$ will be upward biased. The IV approach that we use deals with both sources of endogeneity.

In the main part of the analysis, we use the Heckman two step estimator to get consistent estimates of the causal effect of high level Math on earnings, $\delta$. However, we make extensive robustness checks which show that the conclusions are robust to change of IV estimation method. ${ }^{9}$

Instrumental variables estimation identifies the local average treatment effect (LATE), which is the causal effect of high level Math on earnings for those who are induced to choose high level Math because they were exposed to the pilot scheme. Identification requires that a valid and strong instrument exists, and that the effect of the instrument on the treatment indicator is monotonous in the sense of Imbens and Angrist (1994). ${ }^{10}$ Monotonicity guarantees identification of the LATE, and implies that anyone who would choose high level Math, given that $Z_{i}=z$, would also have chosen high level Math if $Z_{i}=z^{\prime}, \forall z^{\prime}>z$ (or the opposite: $Z_{i}=z^{\prime}, \forall z^{\prime}<z$ ). The instrument is valid if $Z_{i}$ is statistically independent of $\varepsilon_{i}$ and $u_{i}$, and strong if the coefficient to $Z_{i}$ is highly significant in the selection equation (2). ${ }^{11}$ An assignment mechanism which is as good as random assignment ensures that $Z_{i}$ is independent of $u_{i}$. However, it does not

\footnotetext{
${ }^{8}$ See e.g. Levine and Zimmerman (1995) for a related discussion of endogeneity bias.

${ }^{9}$ See Appendix A for details.

${ }^{10}$ See e.g. Imbens and Angrist (1994) for further details, and e.g. Heckman, Tobias and Vytlacil (2001) for an overview of treatment estimators.

${ }^{11}$ According to Staiger and Stock (1997), a good rule of thumb to evaluate whether the instrument is strong is that the t-statistic should be above $\sqrt{10}$.
} 
ensure that $Z_{i}$ is independent of $\varepsilon_{i}$. If $Z_{i}$ is rightfully excluded from (1), it is independent of $\varepsilon_{i}$, and this exclusion restriction ensures that $Z_{i}$ only affects $Y_{i}$ through the effect it has on $M a t h A_{i}$. It is inherently untestable.

While the estimated parameter has predictive power for the subpopulation complying with the instrument, there is no reason to believe a priori that the LATE corresponds to the average treatment effect in the population, ATE, or to the impact of treatment on the treated, TT. ${ }^{12}$ According to Heckman (1997), economically meaningful IV estimates can be found using instruments measuring policy interventions that induce some people to switch participation status while leaving non-switchers unaffected. A zero social cost would then allow us to interpret the LATE as the effect of the marginal policy change on per capita earnings.

\subsection{Two instrumental variables based on a high school pilot scheme}

We use two instrumental variables based on the pilot scheme in high school in the pre-1988 regime to correct for the endogeneity of Math. The pilot scheme reduces the opportunity cost of choosing high level Math since the students are not required to take the Physics course together with advanced Math. Hence, the pilot scheme works as a cost shock that induces more students at the pilot schools to choose high level Math compared to students at non-pilot schools. In this sense, the pilot scheme may be seen as a natural experiment which gives exogenous variation in students' Math qualifications without influencing the outcomes of interest other than through the effect on Math qualifications.

We create two different instruments, each of which exploits the exogenous variation in the exposure of students to the possibility of combining advanced Math courses with advanced Chemistry or not. One instrument is a binary indicator, whereas the other instrument is a continuous distance measure. The two instrumental variables represent two polar cases with respect to the assumption about the selection into high schools: random distribution or self-selection based on potential preference for the experimental curriculum. As will be clear in the next subsection, reality lies somewhere between those two polar cases, which is why we compare the results of using both instruments.

The instrumental variable, PilotSchool ${ }_{i}$, is equal to one if the individual attended a high school which implemented an experimental curriculum allowing advanced Math to be combined with advanced Physics or Chemistry, and zero otherwise. This instrument is valid if individuals are randomly distributed across high schools with and without experimental curriculum. This assumption is violated if students decide upon their branch of studies before enrolling, which may or may not be true. Hence, the assumption rules out that forward looking high school applicants have the opportunity to choose a high school

\footnotetext{
${ }^{12}$ In a homogenous effects model or in a model with heterogeneous effect neither of which is reacted upon by the individuals, the three parameters are identical, see Heckman, Lalonde and Smith (1999). Angrist (2004) also gives alternative sets of homogeneity assumptions under which extrapolation to other populations of interest can be made.
} 
which supplies the experimental curriculum in question. The monotonicity condition requires that individuals, who choose advanced Math when they only can combine it with Physics, will also choose high level Math if they have the option also to combine it with advanced Chemistry. We are confident that the monotonicity assumption is reasonable in our application since all the options available at non-pilot schools are also available at pilot schools.

The instrumental variable, DistPilotSchool $i$, equals the difference between the shortest road distance to the nearest high school with an experimental curriculum and the nearest high school. The instrument proxies the marginal costs of obtaining the option of the experimental curriculum. The assumption for the instrument to be valid is that the additional distance to those high schools is only related to earnings through its effect on the probability of choosing advanced Math. For instance, this assumption rules out that parents initially chose their location based on the geographical placement of high schools with the experimental curriculum, and it also rules out that high schools implementing the experimental curriculum are systematically situated in areas of adolescents with high Math ability. The monotonicity assumption implies that individuals, who choose Math when the extra travel distance is $z$ kilometers, would also choose Math if the additional travel distance were shorter than $z$. If responses are heterogeneous, we also need to assume that the individuals who choose to attend a high school with an experimental curriculum although they live far away, do not make this decision because they have a higher expected Math premium. ${ }^{13}$ All of these assumptions seem reasonable, and we provide corroborative evidence of this in Appendix B.

\subsection{Assignment of students to the pilot scheme}

In the context of the present analysis, it is crucial to understand how individuals are assigned to pilot schools. Two issues are important to understand, namely, how schools become pilot schools, and how individuals sort themselves into pilot schools. Concerning the first issue, schools are not randomly assigned to become pilot schools. In 1986, schools could apply to the Ministry of Education to be allowed to adopt the experimental curriculum, whereas in 1987, the high school rectors were allowed to take the decision without approval from the ministry. Roughly $50 \%$ of the high schools adopted the experimental curriculum. Those schools were evenly spread geographically, and as is clear from Table 1, there are no systematic observed differences between the students at the pilot schools and the non-pilot school other than their Math choice.

Regarding the second issue, individuals are sorted into high schools based on an application which is sent to the preferred school. If admission is not granted by the preferred school, the application is subsequently sent to the school of second priority. All students who have completed nine years of compulsory schooling may be admitted either directly or after passing an entry exam. All qualified applicants are guaranteed admission at a school in the local county. In

\footnotetext{
${ }^{13}$ See the discussion by Heckman, Lalonde and Smith (1999).
} 
the marketing material from the school, it is announced whether they supply the Math-Chemistry branch or not, and the students may take this into account when they apply. Although not binding, the applicants may write in the application that they prefer a given school due to the possibility of choosing the Math-Chemistry combination after their first year. Some students know which branch they prefer before they enroll in high school, others think they know, but change their minds during the first year, and yet others do not know which branch they prefer.

It is difficult to say to what extent the assignment of students to pilot schools is random. However, it is unlikely that the assignment of students to pilot schools is purely random, and hence strictly exogenous with respect to the choice of the Math-Chemistry branch, since we expect that a number of students have applied to enter a certain high school because they want to choose the MathChemistry branch. On the other hand, it is also unlikely that the assignment of students to pilot schools is pure self-selection based on availability of MathChemistry, both because the students would not know which branch they prefer at that point in time, and because other characteristics of the school as well as the travel distance are likely to be important as well.

Table 1 shows that $21 \%$ of the students choose the Math-Physics branch at the non-pilot schools, whereas $18 \%$ and $16 \%$ choose the Math-Physics and MathChemistry branches, respectively, at the pilot schools. If students were purely randomly assigned to high schools, it would imply that $3 \%$ of the students, who would otherwise have chosen Math-Physics, and $13 \%$ of the rest, change their branch choice after being exposed to the pilot scheme. If students decide about their choice of branch before enrolment, and then self-select into high schools purely based on the availability of the pilot scheme, we would expect that the share of Math-Physics students be equal at the pilot schools and the non-pilot schools. In the empirical analysis, we apply two different instruments to check how sensitive the results are to the assumption of random assignment versus self-selection of students into pilot schools.

\subsection{Model specification}

The question arises, which variables should be included among the control variables, $X_{i}$ ? Post secondary schooling is most likely affected by Math qualifications from high school. As discussed by Altonji (1995), Math courses may induce individuals to take longer educations. If Math courses make longer education more profitable, for instance because they are cheaper to acquire because lower efforts are needed, this effect should be attributed to the Math course. By choosing the high level Math course in high school, individuals may enhance the probability of finalizing educations leading to high paying occupations, which would increase $\delta$. First of all, it might be easier to complete an education within the fields of Engineering, Natural Science or Economics, and secondly, the high school graduates simply extend their choice set when it comes to higher educa- 
tion. ${ }^{14}$ On the other hand, the opportunity cost of higher education should be deducted, which means that a number comparable to the real rate of interest should be deducted (Altonji uses $4 \%$ as a maximum on the real rate of interest). ${ }^{15} \mathrm{We}$ are able to distinguish between the direct effect and the total effect (direct plus indirect effect) of Math. ${ }^{16}$ The direct effect of Math on earnings stems from Math affecting for instance logical reasoning and increasing cognitive skills that are useful in most occupations. The indirect effect goes through the enhanced probability of finalizing favorable higher educations, and this effect disappears when we include length and subjects of education in $X_{i}$. To give high level Math full credit for all these effects, the length and subject of higher education should be left out of the regression. In order to obtain an overview of the relationships, we estimate $\delta$ both with and without controls for length and subject of higher education. ${ }^{17}$

A similar issue arises with respect to GPA that may induce a positive or negative bias depending on the relationship between GPA, Math courses and unobserved ability. ${ }^{18}$ GPA is measured during high school with highest weight on the grades obtained in the last year of high school. Hence, it may be affected by high school courses attended. Alexander and Pallas (1984) contradict this presumption by showing that test scores at high school graduation, i.e. in 12th grade, are dominated by the effect of aptitude and prior achievements up until 9 th grade, rather than learning, experience and achievements during high school. Thus, we believe that high school GPA is a reliable measure of aptitude and initial ability at high school entry, and not to any severe extent directly affected by high school courses. However, Albæk (2003) disagrees with this assumption, and therefore, we also estimate $\delta$ both with and without GPA.

Parental background variables are measured at the end of the year before high school entry. Thus, we do not have the same concern that they are influenced by student achievements and course choices during high school. Hence, we control for parental background variables in all our specifications with additional controls. We employ a broad view of human capital investment and allow family background to influence both labor market ability and Math ability.

\footnotetext{
${ }^{14}$ By passing high level Math courses, they can be admitted to university educations within Natural Science and Engineering without supplementary coursework. Up until 1990, even students with medium level math would be admitted without supplementary coursework, although they may have had a harder time following the courses.

${ }^{15}$ We find that there indeed is a positive causal effect of advanced Math on length of highest completed education.

${ }^{16}$ This was done by Ackerman (2000), who found that one third of the total effect of Math on earnings is an indirect effect running through further education.

${ }^{17}$ This approach was also used by Levine and Zimmerman (1995) and Rose and Betts (2004).

${ }^{18}$ See e.g. Levine and Zimmerman (1995) for a related discussion, and e.g. Hansen, Heckman and Mullen (2004) for a more comprehensive discussion of ability bias and the effect of schooling on test scores.
} 


\section{Data}

For our empirical analysis we use a brand new rich panel data set comprising the population of individuals starting high school in the years 1986-89 in Denmark. The data are administered by Statistics Denmark, who have gathered the data from different sources, mainly from administrative registers for the particular purpose of this paper. We select a sample consisting of the cohorts of 1986 and 1987 entering high school before the structural high school reform in 1988.

For each individual, we have data on complete detailed educational histories. These comprehend detailed codes for the type of education attended (level, subject, and educational institution) and the dates for entering and exiting the education, along with an indication of whether the individual completed the education successfully, dropped out or is still enrolled as a student. Furthermore, we have information on the branch choice in high school and high school GPA. ${ }^{19}$ The GPA is a weighted average of the grades at the final exams of each course. Both the quality of the courses and the GPA are comparable across high schools since the control of the high school is centralized at the Ministry of Education. Furthermore, all high school students within each high school cohort are faced with identical written exams, and the oral exams and the major written assignments are evaluated both by the student's own teacher and an external examiner assigned by the Ministry of Education.

Note that there are no tuition fees for education in Denmark, and all students above 18 receive a study grant from the government that suffices to cover living expenses. ${ }^{20}$ Students living with their parents receive a reduced grant, but the grant is independent of parental income, educational effort and achievement as long as the student is less than one year behind scheduled study activity.

We have yearly observations on labor income (earnings), gross income, and net income for the period 1999-2002. All incomes are observed at year-end and deflated to real values measured in year 2000 DKK using the average wage index for the private sector. Other individual background variables that we use in our estimations are gender and actual labor market experience (including a squared term). Parental background variables that we use: include a set of mutually exclusive indicator variables for level of highest completed education of mother and father, respectively, and their income as observed at the end of the year before the individual starts high school. At the same point in time, the shortest road distance to: the nearest high school, the nearest high school offering the option of high level Math in an experimental curriculum, and the high school actually entered, respectively, are calculated (in meters).

Among the gross population of high school entrants of 1986 and 1987, we select only high school graduates completing in three years. ${ }^{21}$ Furthermore, we

\footnotetext{
${ }^{19}$ In Denmark a numerical grading scale system is used. The possible grades are 00, 03, $5,6,7,8,9,10,11,13$, where 6 is the lowest passing grade, and 8 is given for the average performance.

${ }^{20}$ Until 1996, this age limit was 19 years.

${ }^{21}$ We observe $18 \%$ who enter high school without completing in three years. The distribution of dropouts is fairly equal across cohorts, across Math and language tracks, and most
} 
restrict the sample to individuals with non-missing labor market income thirteen years after starting high school, hence, we exclude individuals who have left the country, died, are full-time all year unemployed or out of the labor force. ${ }^{22}$ After these restrictions, the sample contains observations on 13,573 high school graduates who enrolled in 1986, and 14,970 who enrolled in 1987. They come from 139 different high schools.

\subsection{Descriptive Statistics}

The descriptive statistics are shown in Tables 1 and 2. Table 1 shows summary statistics of all background variables, whereas Table 2 shows summary statistics of various outcome variables divided by Math level. Both tables include the mean differences between pilot schools and non-pilot schools.

From Table 1, it is seen that $14 \%$ more students take the advanced Math course at the pilot schools. Furthermore, students who attended a pilot school have $4 \%$ higher earnings. This is likely to be related to the fact that $3 \%$ more of these students have completed a long higher education, in particular within technical fields or social sciences. The (raw) Wald estimate of the effect of Math on earnings is .29 (=.04/.14) without controlling for any explanatory variables.

Table 2 shows descriptive statistics categorized by the indicator of high level Math. Conditional on taking the advanced Math course, the difference between individuals at pilot schools and non-pilot schools slightly favors individuals at non-pilot schools. This picture supports the hypothesis that the group of individuals choosing advanced Math is even more selective at the non-pilot schools where the students are compelled to take advanced Physics to get advanced Math.

Table 2 reveals that high level Math students have very favorable labor market and educational outcomes. They have higher GPA from high school, and more high level Math students attend and complete higher education at any level. Aside from having higher completion rates, high level Math students also complete a given educational level at a faster rate. Hence, high level Math students seem to be more efficient in the higher educational system. In addition, they are more successful after labor market entry as they are less unemployed and earn more. High level Math students' log earnings are .33 higher than the earnings of other high school students. As a point of reference, the Math log earnings gap is more than six times larger than the gender log earnings gap for these high school graduates. Hence, we set out to find out whether this huge earnings gap is due to the fact that students become more productive on the labor market because of the high level Math course, or whether it is due to selection of the students with more favorable unobservable characteristics into the high level Math course.

importantly across pilot schools and non-pilot schools. Most of them drop out during the first year, hence before attending the advanced Math course.

${ }^{22}$ We delete 3,078 individuals due to missing labor income. They are distributed fairly equally across pilot and non-pilot schools, and the estimation results are not sensitive to including these individuals with zero labor income. 


\section{Results}

Aside from presenting the results using IV estimation with our two instruments, we replicate previous studies. This means that we also estimate equation (1) by OLS and by application of a variant of the instrument suggested by Altonji (1995), which is the mean participation rate in the high level Math course at the students' high school year group, HighSchoolMeanMath . $_{\text {. }}$.

\subsection{Estimation of the causal effect of Math on Earnings}

The key outcome variable is (yearly) log earnings thirteen years after starting high school. ${ }^{23}$ The preferred income measure would be lifetime income. However, since the individuals in our sample are relatively young (in their thirties), it is not possible to construct a sensible measure of lifetime income. We believe that the chosen income measure is suitable because individuals on average have been on the labor market for about five years, and hence they are likely to have settled into careers.

A separate note on variables reflecting higher education is needed. As argued in Section 2 above: On the one hand, higher education is a confounder of the direct effect of high school Math on earnings. On the other hand, it is important to control for it, since otherwise we might give high school Math credit for income increases that result from investments of time (and money) in higher education. To take this into account and get an overview of the direct and indirect effects, we run all our estimations with and without controlling for further education. We sequentially include two sets of mutually exclusive indicator variables for highest completed education - one for the level of education categories and one for the level-subject categories, since the cost of a degree as well as the effect of high level Math is presumably not independent of subject of education. ${ }^{24}$ Similarly, we also run all estimations with and without the GPA proxy for aptitude.

To account for differences in earnings profiles, we control for (linear quadratic) actual labor market experience in all specifications with additional explanatory variables. To the extent that high level Math affects employment, actual labor market experience could also be considered a confounder of the direct effect of high level Math. High level Math students are indeed more employed, cf. Table 2 , but in the estimations the effect of the high level Math course is not significantly affected by including (or excluding) actual labor market experience. Furthermore, we do not find evidence of a causal impact of Math on unemployment, whereas we find evidence of a causal impact of Math on length of highest completed education.

\footnotetext{
${ }^{23}$ We have done the analysis using three different income measures: gross income, net income, and labor market income. Furthermore, we have looked at income 12, 13 and 14 years after starting high school, respectively. Our qualitative results are robust to the change of income measure and year.

${ }^{24}$ We have also estimated a specification with years of education, these results were similar, hence not reported.
} 


\subsubsection{Results of estimation}

In Table 3, we replicate previous studies by presenting the estimates of the effect of Math on earnings by OLS and by using the instrument suggested by Altonji (1995). ${ }^{25}$ In the left hand side of the table, the results from OLS show that students who complete the high level Math course in high school receive .33 log points higher earnings. Controlling for parental background variables, labor market experience and gender reduces the Math earnings gap to .25. Also, controlling for GPA further reduces the earnings premium by .03 log points, but this effect vanishes when educational choices are also controlled for. This is what would have been expected given the consistent evidence of individuals self-selecting into educational levels based on ability, see e.g. Willis and Rosen (1979). Furthermore, since GPA is used by educational institutions to screen individuals, it can directly affect further educational choices. The Math effect goes down to .15 after controlling for choices of higher education, and further down to .11 when also controlling for educational subjects. Hence, more than half of the total effect of high level Math on earnings is an indirect effect running through higher education. This indicates that the potential gains from having high level Math are not independent of which length and subject of higher education individuals choose. The result is intuitively compelling since individuals with high level Math will probably be more successful in completing a Science education and other technical educations that traditionally lead to better paid jobs. On the other hand, high level Math students are less likely to choose higher education within Humanities that traditionally leads to lower paid jobs. ${ }^{26}$

In the right hand side of Table 3, we report the results of applying the proportion of (other) high level Math students in the student's high school year group as an instrument for the student's own Math level, HighSchoolMeanMath . $_{\text {. }}$ When we employ this instrument, we find slightly higher estimates of the effect of high level Math on earnings. The estimated IV coefficient measures the effect of those who are induced to take the advanced Math course because they attend a high school where marginally more students attend the high level Math course. The total effect is .41, but diminishes to .21 when controlling for all background characteristics. Although the instrument has a high predictive power of attending the high level Math course, it is not considered a clean instrument for several reasons (cf. Section 1). ${ }^{27}$

PilotSchool In Table 4, we present results of IV estimation with the pilot scheme based instruments. In the left hand side of the table, we present estimates using the instrument, PilotSchool $i$, which is an indicator for enrollment in a high school offering the experimental curriculum. The IV estimate without

\footnotetext{
${ }^{25}$ We have also estimated the model with high school FE, which shows almost identical results (available upon request). This was also to be expected since the centralized control of the high schools means that the course quality is very similar across high schools.

${ }^{26}$ Descriptive statistics confirming these two presumptions are not reported, but available upon request.

${ }^{27}$ The t-statistics in the selection equation (2) are around 35.
} 
explanatory variables shows a significant positive total effect of .26 of advanced Math on earnings. When we control for parental background characteristics, advanced Math has an even larger positive causal impact. Hence, the students choosing high level Math because they have the option of combining it with advanced Chemistry instead of Physics have relatively unfavorable background characteristics. The coefficient goes further up to .32 when GPA is added, meaning that the individuals choosing high level Math because they may combine Math with Chemistry instead of Physics also have relatively unfavorable characteristics in terms of GPA. When we include measures of length of further education, the effect of Math is reduced by more than half of the total effect, while it is only reduced by about one third when also controlling for subject of further education. We conclude that about half of the causal effect of Math on earnings is an indirect effect which goes through the effect on attained higher education. This effect may stem from changed preferences for length and subject of education ${ }^{28}$, or it may stem from improved skills to complete favorable educations. Individuals who are induced to choose high level Math because they are exposed to the experimental curriculum end up with longer educations than they otherwise would have gotten. ${ }^{29}$ Note that once parental background variables are conditioned on, we find remarkably similar results employing Altonji's instrument and our PilotSchool..$^{30}$ This is probably because the dominant variation in Altonji's instrument in our setting comes from the variation between pilot schools and non-pilot schools.

DistPilotSchool The right hand side of Table 4 presents the results for the instrumental variables estimation using DistPilotSchool as an instrument for Math. DistPilotSchool is a continuous distance variable measuring the difference between the shortest road distance to the nearest high school offering the experimental curriculum and the shortest road distance to the nearest high school (measured in 10 kilometers $\sim 6$ miles). For these estimations, we exclude the 508 individuals for whom DistPilotSchool cannot be computed because information about the place of residence of the parents before the individual entered high school is not available. The estimated coefficients are very large and the precision is low since the t-statistics on the coefficients applying to the instruments in the selection equation (2) are only around 9. The main conclusion from these estimates is that there are indications of a positive causal effect, and we reject that the effect is zero. The coefficient estimates vary much in the same fashion for the two instruments. As for PilotSchool, the IV-estimates based on DistPilotSchool indicate an additional effect on earnings on top of the effect on higher educational choices since the estimate is significantly positive

\footnotetext{
${ }^{28}$ Which would be consistent with Arcidiacono (2004).

${ }^{29}$ Descriptive statistics (available upon request) show that the individuals who choose Math in combination with Chemistry to a lower extent choose Technical subjects and Natural Sciences compared to the students who choose Math in combination with Physics. Instead, they choose Health Science and Social Science.

${ }^{30}$ Both instruments are found to be strong instruments with t-statistics above 36 and 25 , respectively, in the selection equation (2) for all specifications.
} 
after accounting for length and subject of education. However, precision is too low to draw inference on the exact magnitude of the effect.

\subsubsection{Robustness tests}

In this section, we provide various tests of the robustness of our results and the validity of the pilot scheme based instruments. Unless otherwise noted, the results are not tabulated here, but available upon request.

Math track only To get a potentially more clean estimate of the effect of taking the advanced Math course in the last year of high school, we estimate all our specifications for the subsample of high school graduates on the Math track. In Table 1, it is seen that $68 \%$ of high school graduates chose the Math track. All students on the Math track have at least medium level Math. As expected, the raw Math earnings premium is slightly smaller if we look at Math track students only, and the causal impact is also slightly smaller. However, the qualitative conclusions also hold for this subsample.

Stratification To check how robust the conclusions are across subsamples, we have stratified the sample according to a number of criteria. If we subdivide by subject of highest completed education, the effect of Math is zero for Humanities in all but a few estimations including the OLS. ${ }^{31}$ For Technical and Natural Sciences it follows exactly the same pattern as the main results (with slightly larger positive effects), whereas for Health Sciences and for Social Sciences the picture is similar but the effects are smaller. We interpret these results as affirmative of the conclusions drawn so far that the Math premium is closely related to the choice of higher education. It indicates that specific skills are learned in the Math course that apply more directly to some educations and jobs.

Length of Education To the extent that high level Math increases success in higher education, the social gains of a higher Math level in general may prove to be larger than the estimated earnings gains. Higher education has many benefits other than higher earnings, such as better health outcomes and lower crime rates. ${ }^{32}$ High school graduates with high level Math have on average ten months longer education, cf. Table 2 . This positive correlation indeed reflects a causal effect of Math on length of highest completed education. Instrumenting Math qualifications by PilotSchool reveals a total causal impact of as much as eleven months longer education for those students who choose Math because they are able to combine it with advanced Chemistry. When controlling for parental background and GPA, the causal impact is slightly more than one year

\footnotetext{
${ }^{31}$ If high level Math students had learned skills that made them more able to successfully complete postsecondary education within the Humanities as is often claimed, this effect should be positive. Skills such as clarity in expressions, logical reasoning and inference, as well as imagination and ingenuity, should prove to be powerful tools for completing a higher education in any field.

${ }^{32}$ See e.g. Currie and Moretti (2003) and Lochner and Moretti (2004).
} 
longer education for the complying students. For DistPilotSchool, the causal impact of Math is only significant when controlling for parental background and GPA, then it is also as large as eleven months.

Unemployment Another seemingly beneficial effect of the high level Math course is that the unemployment level among these individuals is lower 13 years after starting high school. ${ }^{33}$ Measuring the unemployment level during the year on a scale from 0 to 1000, high school graduates with high level Math have an average unemployment level of 15.6 below that of other high school graduates, i.e. they are on average unemployed $1.56 \%$ less of the year, cf. Table 2. As a robustness check, we estimate the effect of high level Math on the unemployment level for the total estimation sample of high school graduates. The OLS estimates reveal a negative correlation between attending the high level Math course and unemployment level, as they indicate that high level Math students are on average almost one week less unemployed during the year. However, the IV estimates do not lend much support for this to be a causal effect for the subsample complying with the instruments. ${ }^{34}$

Alternative IV methods In Appendix A, we present a range of estimates based on alternative instrumental variables methods used in the literature. As shown in Table A1, our conclusions are robust to change of IV estimation technique.

Miscellaneous tests In Appendix B, we present a range of tests: (i) We estimate the implied bias on the estimates according to Altonji, Elder and Taber (2004). The idea is to find a subsample for whom the advanced Math course is not a serious option, and then check whether the earnings of this subsample is influenced by the instrument. The language track students constitute such a subsample. We find that there is no direct effect of the instrument on earnings since the implied biases are small and statistically insignificant for all specifications. Hence, we are confident that the exclusion restriction holds, and hence that the causal effects estimated by the pilot scheme instrumental variables are internally valid. (ii) We use various tests to get an indication of the source of selection bias, e.g. the Durbin-Wu-Hausman test for no selection bias, and the so-called "difference-in-Sargan" test for overidentifying restrictions. The latter to test whether it can be ruled out that individuals select advanced Math based on their expected potential gains in outcomes. This is important in order to meet the critique against distance instruments raised by Heckman, Lalonde and Smith (1999). Likewise, Heckman (1997) points out that LATE equals ATT only when the students complying with the reform do not make the decision

\footnotetext{
${ }^{33}$ This is also the case if we consider the unemployment level twelve or fourteen years after starting high school.

${ }^{34}$ These results are in line with Holler, Høst and Kristensen (1992) who find that decision makers with a mathematical background tend to choose more secure strategies than decision makers with a non-mathematical background.
} 
to choose advanced Math based on factors that also determine the gains from attending the advanced Math course.

We cannot reject that there is selection bias. However, the selection on expected earnings does not seem to be an issue for the pilot scheme based instruments. To conclude, the employed tests neither give us reason to doubt that the estimated causal effects are internally valid for the populations complying with the instruments, nor that they can be used for making predictions for other populations.

\subsubsection{Discussion}

When we employ the exposure to experimental curriculum as an instrumental variable, PilotSchool, we find a positive causal effect of Math which is significantly reduced when we control for length and subject of education. This result may be due to favorable synergy effects of Math and Chemistry, or it may be due to the fact that the Chemistry-Math combination influences the students' further career choices and career success in direction of well-paid jobs. The instrument identifies the causal effect for individuals who are induced to choose advanced Math because they are able to combine it with advanced Chemistry rather than advanced Physics. We conclude that there is a positive causal effect of Math for this group, which mainly is an indirect effect going through choice of higher education. The compliers in the treatment group are unidentifiable. They consist of a combined group of people who would otherwise have preferred to take a medium level Math course in combination with either advanced Social Science, advanced Biology or advanced Music courses (see Figure 3a and 3b). Supplied with the option of choosing advanced Chemistry, the complying students end up with advanced Math and advanced Chemistry which leads them to a different future career choice. Because advanced Math and advanced Chemistry are combined in a course bundle, we cannot separate the effect of advanced Math from that of advanced Chemistry. The earlier literature suggests that if any specific course work matters, it is Math rather than Science courses. ${ }^{35}$

When we employ the distance based measure proxying the costs of obtaining the option to take the experimental curriculum, DistPilotSchool, we find a positive significant effect which follows the same pattern, but is not as precisely estimated. We interpret these results as evidence that the positive causal effect of Math is not mainly driven by self-selection into high schools supplying Math in combination with Chemistry.

Corroborating with this, the descriptive statistics of high school proximity and choices in Table 5 reveal that most students choose to attend the nearest high school: $66 \%$ choose the nearest high school, and for $71 \%$ that choose a pilot school, it is the nearest high school. Furthermore, students on pilot schools live on average $.4 \mathrm{~km}$ farther from the nearest high school and $8.6 \mathrm{~km}$ closer to the nearest pilot school. Correspondingly, the average pilot school student actually travels $.2 \mathrm{~km}$ shorter to school. Table 5 also reveals that students in rural areas

${ }^{35}$ See Altonji (1995), Levine and Zimmerman (1995) and Rose and Betts (2004). 
have longer travel distances and more of them choose the nearest high school. ${ }^{36}$

Accordingly, PilotSchool is our preferred instrument. A position intensified by the fact that the estimates of the causal effect of Math applying PilotSchool as an instrument are not sensitive to including DistPilotSchool as a control. As opposed to the other way around. These results are displayed in the first two parts of Table 6 for three of our seven specifications: (1) no controls, (2) only controlling for gender, labor market experience, and parental background variables, and (4) additionally controlling for categories of length of highest completed education. The last part of Table 6 presents the results of IV estimation using the interaction term PilotSchool * DistPilotSchool as an instrument for these same three specifications. If tastes for Math depend strongly on preferences for PilotSchool, then PilotSchool * DistPilotSchool will have an effect on high level Math choices that is independent of the separate effects of PilotSchool and DistPilotSchool. In particular, Math choices are likely to be much more sensitive to DistPilotSchool for individuals with a preference for PilotSchool. However, we find that this is not the case. Applying PilotSchool * DistPilotSchool as an instrument, while controlling for PilotSchool and DistPilotSchool, we find that the instrument is insignificant in the selection equation (2) in all specifications. Furthermore, PilotSchool and DistPilotSchool are highly significant in the selection equation (2), but insignificant in the earnings equation (1). Hence, we have no reason to believe that high school choice is driven by preferences for PilotSchool.

The final evidence corroborating the validity of the PilotSchool instrument applies information about the post-reform cohorts that enter high school in 1988 and 1989. Students that attend the former pilot schools should not have a different likelihood of choosing high level Math than the ones at non-pilot schools. This is also what we find when we let $H S 88$ be an indicator for entering high school after the reform of 1988, and apply PilotSchool $* H S 88$ as an instrument while controlling for PilotSchool and HS88 main effects.

To sum up, we find that students are as good as randomly distributed across pilot and non-pilot high schools, respectively, and we find no reason to believe that high school Math choices are driven by preferences for the pilot scheme. Furthermore, we find no earnings effect of exposure to the pilot scheme for subgroups that by construction should not be affected. Consequently, we are confident that the exclusion restriction holds, and that PilotSchool is a valid instrument.

In the light of Appendix B, we are also confident using the internally valid estimates for extrapolation. If we want to know the causal effect of the high level Math course on a randomly chosen high school graduate, we need to know the ATE. According to Angrist (2004) and Oreopoulos (2006), the more students' Math choices are affected by the instrument, the closer is the LATE to the ATE. Hence, given the large size (and high precision) of the PilotSchool instrument, the LATEs should ceteris paribus be close to the ATE. Furthermore, Heckman

\footnotetext{
${ }^{36}$ All our estimation results are robust to stratifying the estimation sample into students living in rural areas vs. urban areas.
} 
and Vytlacil (2000) and Angrist (2004) point out that when the latent error distribution is symmetric, the LATE equals ATE if the binary instrument affects the choice probability symmetrically, i.e. $P\left(\right.$ Math $_{i}=1 \mid$ PilotSchool $\left._{i}=0\right)=$ $1-P\left(\right.$ Math $_{i}=1 \mid$ PilotSchool $\left._{i}=1\right)$, which would hold true if the exposure to the reform switches the probability of choosing the high level Math course from e.g. .30 to .70 . Our sample does not satisfy the symmetry condition. The PilotSchool instrument switches the fraction with high level Math from .21 to .35 , in which case we find a positive effect. For the subsample of males, the PilotSchool instrument switches the fraction with high level Math from .35 to .50 , in which case we also find a positive effect (not reported, but available upon request $)$. Because $P\left(\right.$ Math $_{i}=1 \mid$ PilotSchool $\left._{i}=0\right)<1-P\left(\right.$ Math $_{i}=$ $1 \mid$ PilotSchool $\left._{i}=1\right)$, the positive effect is estimated for a sample slightly to the right of the median, we cannot say whether the ATE is also positive.

Finally, we impute the ATEs. The predictions are almost identical for the two pilot scheme based instruments, which is reassuring since the ATE by definition is invariant to the particular instrument. We find that the ATE is .33. Conditional on gender, labor market experience, and parental background characteristics, it is .25, if we further condition on length of highest completed education, it is .14, and also controlling for subject of highest completed education gives an ATE of .10.

The main conclusion from this analysis is that the causal impact of Math is positive, at least for some relevant subgroups, namely individuals who combine advanced Math with other advanced Science courses. Part of the effect is indirect going through choice of higher education. Hence, our results confirm the beneficial effects of coupling Math with related courses in order to extract potential synergy effects. This effect is also very likely to be representative of the effect on a randomly chosen high school student.

\section{Conclusion}

Knowing the causal effect of Math on labor market and educational success is imperative for an informed debate about high school curricula. In particular, this information is important in order to shed more light on issues such as the decisions about which coursework should be mandatory and which should be optional, and about the minimum required level of Math taught in high school.

In order to estimate the causal impact of Math, we employ two new instruments based on the pilot scheme in the Danish high school in the pre-1988 regime, which reduced the costs of taking advanced Math. We use data for the 1986-87 high school cohorts which includes information on educational event histories, demographic information and parental background variables.

It is well-known that students who choose high level Math courses have more favorable characteristics on average. In particular, we find that they have a $30 \%$ higher labor income thirteen years after high school, and conditional on a large set of observable characteristics, their earnings premium is around $10 \%$. When we estimate the effect of the advanced Math course on earnings by 
IV methods, we find a positive causal impact for a policy-relevant subgroup of the population, namely those who are induced to choose advanced Math when it may be combined with advanced Chemistry rather than advanced Physics. Part of the effect is indirect and goes through choice of higher education. Hence, the individuals who are induced to choose advanced Math with other advanced Science courses either seem to change their preferences for education, or they seem to acquire extra human capital resulting in an earnings premium.

Although informative for the political debate, it is important to note that our conclusion might not hold irrespective of age and time. We analyze earnings thirteen years after high school entry, and benefits might change later in the life cycle. Furthermore, the economic environment is not static, and the valuation of different types of skills may change over time. Finally, due to dynamic complementarities, there might be a causal effect from teaching pupils more Math at earlier stages than high school. Nevertheless, we interpret our results as adding on to the empirical evidence of the existence of a positive causal impact of Math on earnings. 


\section{References}

[1] Ackerman, D. (2000), Do the Math: high school Mathematics Classes and Lifetime Earnings of Men. Manuscript. U of Wisconsin - Madison.

[2] Arcidiacono, P. (2004), Ability Sorting and the Returns to College Majors, Journal of Econometrics, 121:1-2, 343-375

[3] Albæk, K. (2003), Optimal adgangsregulering til de videregående uddannelser og elevers valg af fag i gymnasiet (Optimal admissions policy for higher education and choice of high school subjects), Nationaløkonomisk Tidsskrift, 141:2, 206-224.

[4] Alexander, K. L. and A. M. Pallas (1984), Curriculum Reform and School Performance: An Evaluation of the "New Basics", American Journal of Education, (August 1984): 391-420.

[5] Altonji, J. (1995), The Effect of high school Curriculum on Education and Labor Market Outcomes, Journal of Human Resources, 30 (3): 409-438.

[6] Altonji, J., T. Elder and C. Taber (2004), An Evaluation of Instrumental Variable Strategies for Estimating the Effects of Catolic Schooling, working paper, Northwestern University.

[7] Angrist, J. D. (2004), Treatment Effect Heterogeneity in Theory and Practice, The Economic Journal, 114: C52-C83.

[8] Baum, C. F., M. E. Schaffer and S. Stillman (2003), Instrumental Variables and GMM: Estimation and Testing, Boston College Working Paper No.545.

[9] Blackburn, M. L. and D. Neumark (1993), Omitted-Ability Bias and the Increase in Returns to Schooling, Journal of Labor Economics, 11: 521-544.

[10] Bowles, S., H. Gintis and M. Osborne (2001), The Determinants of Earnings: A Behavioural Approach, Journal of Economic Literature, 39: 11381176.

[11] Cameron, S. and J. J. Heckman (1993), Nonequivalence of High School Equivalents, Journal of Labor Economics, 11: 1-47.

[12] Currie, J. and E. Moretti (2003), Mother's Education and the Intergenerational Transmission of Human Capital: Evidence from College Openings, Quarterly Journal of Economics, 118 (4): 1495-1532.

[13] Hansen, K. T., J. J. Heckman and K. J. Mullen (2004), The Effect of Schooling and Ability on Achievement Test Scores, Journal of Econometrics, 121: 39-98.

[14] Hanushek, E. A. and D. D. Kimko (2000), Schooling, Labor-Force Quality and the Growth of Nations, American Economic Review, 90(5): 1184-1208. 
[15] Heckman, J. J. (1997), Instrumental Variables: A Study of Implicit Behavioral Assumptions Used In Making Program Evaluations, The Journal of Human Resources, 32(3): 441-462.

[16] Heckman, J. J., R. J. Lalonde and J. A. Smith (1999), The Economics and Econometrics of Active Labor Market Programs, Ch. 31 in O. C. Ashenfelter and D. Card (eds.), Handbook of Labor Economics Vol 3A. Elsevier.

[17] Heckman, J. J. and E. Vytlacil (2000), Local Instrumental Variables, NBER Technical Working Paper No.252.

[18] Heckman, J. J., J. L. Tobias and E. Vytlacil (2001), Four Parameters of Interest in Evaluation of Social Programs, Southern Economic Journal 68(2): 210-223.

[19] Holler, M. J., V. Høst and K. Kristensen (1992), Decisions on Strategic markets - an Experimental Study, Scandinavian Journal of Management, 8(2): 133-146.

[20] Imbens, G. W. and J. D. Angrist (1994), Identification and Estimation of Local Average Treatment Effects, Econometrica, 62(2): 467-475.

[21] Lee, J.-W. and R. J. Barro (2001), Schooling Quality in a Cross-Section of Countries, Economica, 68: 465-488.

[22] Levine, P. B. and D. J. Zimmerman (1995), The Benefit of Additional HighSchool Math and Science Classes for Young Men and Women, Journal of Business and Economic Statistics, 13(2): 137-149.

[23] Lochner, L. and E. Moretti (2004), The Effect of Education on Criminal Activity: Evidence from Prison Inmates, Arrests and Self-Reports," NBER Working Paper No. 8605, November 2001, and American Economic Review, 94 (1): 155-189.

[24] Murnane, R. J., J. B. Willett and F. Levy (1995), The Growing Importance of Cognitive Skills in Wage Determination, The Review of Economics and Statistics, 251-266.

[25] Oreopoulos, P. (2006), Estimating Average and Local Average Treatment Effects of Education when Compulsory Schooling Laws Really Matter, The American Economic Review, 96(1): 152-175.

[26] Perna, L. W. and M. A. Titus (2004), Understanding Differences in the Choice of College Attended: The Role of State Public Policies, Review of Higher Education, 27(4): 501-525.

[27] Petersen, P. B. and S. Vagner (2003), Studentereksamensopgaver i matematik 1806-1991, Matematiklærerforeningen.

[28] Rose, H. and J. R. Betts (2004), The Effect of high school Courses on Earnings, The Review of Economics and Statistics, 86(2): 497-513. 
[29] Roy, A. (1951), Some Thoughts on the Distribution of Earnings, Oxford Economic Papers, 3: 135-146.

[30] Sargan, J. (1958), The Estimation of Economic Relationships using Instrumental Variables, Econometrica, 26(3): 393-415.

[31] Staiger, D. and J. H. Stock (1997), Instrumental Variables Regression with Weak Instruments, Econometrica 65(3) p.557-586.

[32] Vella, F. and M. Verbeek (1999), Estimating and Interpreting Models With Endogenous Treatment Effects, Journal of Business and Economic Statistics, 17(4):473-478.

[33] Vytlacil, E. (2002), Independence, Monotonicity, and Latent Index Models: An Equivalence Result, Econometrica, 70(1): 467-476.

[34] Willis, R. J. and S. Rosen (1979), Education and Self-Selection, Journal of Political Economy, 87: S7-S36.

[35] Wooldridge, J. M. (2001), Econometric Analysis of Cross Section and Panel Data, Cambridge, MA: MIT Press.

[36] Zangerberg, C. U. and H. E. Zeuthen (1997), Den Hvide Hue: Hvad Fører den til?, Statistics Denmark. 


\section{A Appendix}

In this Appendix, we provide evidence that our IV estimates are robust to the precise estimation method chosen.

\section{A.1 Sensitivity Analysis of IV estimates}

As the basic case we report the two step IV estimator presented in Section 4, where probit estimates of the Math selection equation (2) are obtained in the first step, and in the second step, the earnings equation (1) is augmented by the generalized probit residuals, $\gamma_{i}{ }^{37}$ and then the structural parameters of the outcome equation (1) are consistently estimated by OLS. The difference between this IV method and the conventional IV method ${ }^{38}$ is that the conventional IV estimator is obtained by augmenting the earnings equation by the least squares residuals (instead of the generalized probit residuals). As a sensitivity analysis of our IV results, we reestimate all our specifications using other IV methods. Roughly speaking, the IV methods that we apply have different ways of correcting for endogeneity bias, hence allowing for different types of selection mechanisms. Therefore, the underlying identifying assumptions are somewhat distinct, but basically comparable. ${ }^{39}$ We find that the method we apply is general enough to capture the main selection mechanisms that potentially lead to endogeneity bias in the estimated effect of Math courses, and simple enough to be transparent and intuitively clear.

The results from the estimation of the causal effect of high level Math are found in Table A1 where PilotSchool $i$ is applied as the instrument. The five different IV estimation methods presented in the rows of the table are: Conventional IV ( Math $_{i}$ instrumented by PilotSchool ${ }_{i}$ ), IV Method 1 (Math $A_{i}$ instrumented by the first step probit choice probability $\Phi(\odot)$ ), IV Method 2 $\left(\right.$ Math $A_{i}$ instrumented by the first step probit choice probability $\Phi(\cdot)$, furthermore, interaction terms $M a t h A_{i}\left(X_{i}-\bar{X}\right)$ are allowed for, and instrumented by $\left.\Phi(\cdot)\left(X_{i}-\bar{X}\right)\right)$, at last $\phi(\cdot)$ is also included), IV Method 3 is the most general version of the IV method we have applied previously, here the outcome equation is augmented by the interaction terms $\operatorname{Math}_{i}\left(X_{i}-\bar{X}\right), \operatorname{Math} A_{i} \cdot \gamma_{1 i}$ and $\left(1-\right.$ Math $\left.A_{i}\right) \cdot \gamma_{0 i}$ and then consistently estimated by OLS, and finally IV Method 4 is a slightly more general version of the IV method we have applied previously, here the outcome equation is augmented by the interaction terms $M a t h A_{i} \cdot \gamma_{1 i}$ and $\left(1-M a t h A_{i}\right) \cdot \gamma_{0 i}$ and then estimated by OLS. The first row of the table redisplays our previous IV estimates as a point of comparison (here the outcome equation is augmented by the the hazard $\gamma_{i}=$ Math $A_{i} \cdot \gamma_{1 i}+\left(1-\right.$ Math $\left.A_{i}\right) \cdot \gamma_{0 i}$

\footnotetext{
37

$$
\gamma_{i}=\left\{\begin{aligned}
\gamma_{1 i}=\frac{\phi\left(\widehat{\alpha}_{0}+\widehat{\alpha}_{1} X_{i}+\widehat{\theta} Z_{i}\right)}{\Phi\left(\widehat{\alpha}_{0}+\widehat{\alpha}_{1} X_{i}+\widehat{\theta} Z_{i}\right)}, & \text { if } \operatorname{Math} A_{i}=1 \\
\gamma_{0 i}=\frac{-\phi\left(\widehat{\alpha}_{0}+\widehat{\alpha}_{1} X_{i}+\widehat{\theta} Z_{i}\right)}{1-\Phi\left(\widehat{\alpha}_{0}+\widehat{\alpha}_{1} X_{i}+\widehat{\theta} Z_{i}\right)}, & \text { if } \operatorname{Math} A_{i}=0
\end{aligned}\right.
$$

${ }^{38}$ Here we refer to two stage least squares (2SLS) as the conventional IV method.

${ }^{39}$ See e.g. Vella and Verbeek (1999), Wooldridge (2001) or Vytlacil (2002) for a more comprehensive discussion.
} 
and estimated by OLS). The conventional IV estimator only allows for restrictive forms of endogenous selection. Only if the gain from the high level Math course does not vary across individuals, or the expected gain is unobserved to the individual when choosing the course, the ATEs are identified. IV Method 1 requires the same for identification, but is more efficient. Allowing for heterogeneous gains from Math is notably harder, and this problem has been studied by e.g. Heckman (1997). Nevertheless, it can be done using either IV Method 2 or IV Method 3, where the former is most robust, and the latter relies on a normality assumption for identification. ${ }^{40}$ Furthermore, IV Method 2 allows us to separate the issue of endogenous and nonconstant treatment effects by testing the significance of the coefficient on $\phi(\widehat{*})$. We find that it is only significant in the specifications where we control for the level-subject categories of higher education, i.e. nonconstant treatment effects only seem important given subject of postsecondary education. Hence, the gains that high school graduates get from the high level Math course depend on the chosen subject of postsecondary education. This is also consistent with what we deduced from our results in Section 6. One advantage of IV Methods 3 and 4 (and also the one we apply) is, however, that they estimate a number of additional parameters that provide us with information about the self-selection mechanism. The results from IV Method 2 deviate most from our previous results as the effect of Math is not always found to be significantly larger than zero. It should be noted, however, that IV Method 2 may not be well specified in our settings due to collinearity issues. Not surprisingly, IV Method 4 gives estimates closest to the ones we previously found. Overall, it is reassuring that our main conclusions regarding the causal effects do not change significantly depending on the particular IV estimation method chosen.

\section{B Appendix}

In this Appendix, we provide tests of the validity of the instruments, selection effects and heterogeneous treatment effects.

\section{B.1 Testing Validity of Instruments}

In this section, we corroborate that PilotSchool is a valid instrument. First, we examine whether the pilot schools differ in systematic ways from non-pilot schools. This is done by comparing the observable characteristics of the high school graduates and their parents. Second, we attempt to estimate the implied bias in the causal effect by looking at the effect of PilotSchool $_{i}$ for high school graduates with language based studies for which the advanced Math course is not a serious option.

\footnotetext{
${ }^{40}$ One might say that it is a trade-off between non-normality against robustness and efficiency.
} 


\section{B.1.1 Comparing the pilot schools to non-pilot schools}

If individuals are randomly assigned to pilot schools because of exogenous variation due to place of residence and preferences for other school characteristics, any observed differences would solely be attributed to the fact that choices of high school Math courses differ between the two cohorts. However, if there are systematic and significant differences between observable characteristics of the two high school cohorts before they start high school, one might question that the two cohorts have similar distributions of unobservable labor market and math abilities. Therefore, we compare the primary school attendance and parental background variables of the two high school cohorts before high school entry. The descriptive statistics in Table 1 do not give us any reason to believe that the students at the pilot schools differ in any respect from those at the nonpilot schools. In other words, students seem fairly randomly distributed across pilot and non-pilot schools that do and do not offer experimental curriculum with advanced Math.

We also look closely at the characteristics of students at pilot schools versus non-pilot schools after 1988 when the pilot scheme was no longer in action. We find no observed differences.

\section{B.1.2 Implied Bias of IV estimates}

Now we try to directly estimate the implied bias in the estimated causal effects. Following Altonji, Elder and Taber (2004), who evaluate IV estimation strategies for estimating the effects of Catholic schooling, we identify a sample of individuals for whom the high level Math course is not a serious option. Hence, we take advantage of the fact that the high school students who, upon high school entry, choose the language track have zero probability of attending the high level Math course, see Figure 2. Let $M_{i}$ be an indicator variable equal to one if individual $i$ chooses Math track $\left(M_{i}=1\right)$, and equal to zero if $i$ chooses the language track $\left(M_{i}=0\right)$ upon high school entry. Then $P\left(M a t h A_{i}=1 \mid M_{i}=0\right)=0$. Furthermore, we assume that the joint distribution of $\left(X_{i}, Z_{i}, \varepsilon_{i}\right)$ is independent of $M_{i} \cdot{ }^{41}$

It is well known that the conventional IV estimate of the causal effect of high level Math on earnings, $\delta$, converges to:

$$
\delta_{I V} \stackrel{p}{\rightarrow} \delta+\frac{\operatorname{cov}\left(\widetilde{Z_{i}}, \varepsilon_{i}\right)}{\theta \operatorname{Var}\left(\widetilde{Z_{i}}\right)},
$$

\footnotetext{
${ }^{41}$ The descriptives in Table 1 reveal that changes in the self-selection mechanism of students between math and language tracks might be induced by the pilot scheme as $34 \%$ of the students at non-pilot schools and $30 \%$ pilot schools choose the language track. However, since these differences are similar in the post-reform cohorts entering high school in 1988 and 1989, there does not seem to arise a potential selection problem by restricting the analysis to the sample of high school graduates from the language track, and we do not account for potential correlation between $Z_{i}$ and $\varepsilon_{i}$, induced by conditioning on $M_{i}$.
} 
where $\widetilde{Z}_{i}$ is the residual from the projection of $Z_{i}$ on $X_{i}$. Since we have a consistent estimate of $\theta$ from the first stage estimation, a consistent estimate of the bias, $\xi=\frac{\operatorname{cov}\left(\widetilde{\left.Z_{i}, \varepsilon_{i}\right)}\right.}{\theta \operatorname{Var}\left(\widetilde{Z}_{i}\right)}$, can be obtained by estimating the equation:

$$
y_{i, 13}=\pi_{1} X_{i}+\left(\widehat{\theta} Z_{i}\right) \xi+v_{i}
$$

by OLS on the sample of high school graduates from the language track. The parameter estimate of $\xi$ is then a consistent estimate of the implied bias.

Table B1 shows the estimated biases along with the estimated IV coefficients as a point of reference. The bias tends to be positive for PilotSchool, however, insignificant in all specifications. This indicates that the positive causal effect of advanced Math for the students who are induced to choose advanced Math combined with Chemistry can be considered an upper bound. Since all the implied biases are statistically insignificant, we are confident that our instrument, PilotSchool, is indeed a proper instrument.

\section{B.2 Tests of Homogeneity Assumptions}

In this section, we corroborate the validity of the pilot scheme based instruments as a basis for extrapolation. The analysis in the preceding subsection has established that the reform based instruments estimate internally valid causal effects. However, in order to make inference for other populations, the causal effects have to satisfy some additional homogeneity assumptions in order for LATE to equal ATE. In this subsection, we test two of these assumptions: ${ }^{42}$ First of all, if there was no selection bias (or equivalently constant effects), then of course LATE would equal ATE and ATT. The assumption of no selection bias can be tested by the Durbin-Wu-Hausman (DWH) test which is equivalent to the more efficient test proposed by Angrist (2004) under the monotonicity assumption. The tests show that the hypothesis of no selection bias does not seem credible in our application.

The second homogeneity assumption is that of conditional constant effects, which allows for selection bias in the sense that $Y_{1 i}$ and $Y_{0 i}$ are allowed to be correlated with potential participation in the advanced Math course. However, $Y_{1 i}-Y_{0 i}$ is orthogonal to potential participation, i.e. it is restricted to be the same for both potential outcomes. This assumption is consistent with absolute advantage, but rules out comparative advantage, i.e. Roy (1951) type of selection, where the choice of the advanced Math course is determined by the potential gains from completing the course. Hence, the conditional constant effect assumption implies that the ATE is the same, regardless of a student's likelihood of choosing advanced Math. Since the ATE (by definition) is invariant to the particular instrument applied to estimate it, the underlying idea of the test is to compare the estimated ATEs using different instruments. Under the assumption of conditional constant effects, this test amounts to a Sargan

\footnotetext{
${ }^{42} \mathrm{~A}$ more comprehensive description of homogeneity assumptions and tests can be found in e.g. Angrist (2004) and Baum, Schaffer and Stillman (2003).
} 
(1958) test for over-identification. The drawback of this test is that it can only be applied if we have more excluded instruments than endogenous control variables, and that it tests for the failure of any of the instruments to satisfy the orthogonality conditions. In the case of the pre-reform cohorts, we can more reliably employ a "difference-in-Sargan" test statistic, which in effect is computed as the difference between two Sargan test statistics (that for the regression using the entire set of overidentifying restrictions, and that for the regression using a smaller set of restrictions from which a specified instrument is removed). Hence, it allows us to test that the specified instrumental variable satisfies the orthogonality condition. This test can only reject the conditional constant effect assumption for PilotSchool in the specification without any exogenous control variables with a p-value of 0.008 . For all other specifications, the hypothesis that PilotSchool satisfies the orthogonality condition cannot be rejected at any usual levels of significance (all p-values $>0.667$ ). Similarly, for DistPilotSchool, the hypothesis cannot be rejected for any specification (all p-values $>0.19$ ). To conclude, we do not find any reason to doubt the conditional constant effect assumption, and accordingly, we believe that we can trust extrapolations of ATEs estimated by instruments PilotSchool and DistPilotSchool. Note that the symmetry assumption discussed in Section 6.1.3 implies a less restrictive homogeneity assumption than the assumption of conditional constant effects, namely, that the conditional expectation of the potential outcomes is a linear function of $M a t h A_{0 i}+\operatorname{Math} A_{1 i}$. 
Table 1. Descriptive Statistics of Dependent and Explanatory Variables for Estimation Sample.

\begin{tabular}{|c|c|c|c|}
\hline \multirow[b]{2}{*}{ Variable } & \multicolumn{3}{|c|}{$\begin{array}{c}\text { Means and (standard deviations) } \\
\text { All }\end{array}$} \\
\hline & \multicolumn{2}{|c|}{ Overall mean } & $\begin{array}{c}\text { Mean } \\
\text { difference by } \\
\text { PilotSchool } \\
\end{array}$ \\
\hline Educational variables: & \multirow{2}{*}{\multicolumn{2}{|c|}{0.27}} & \multirow[b]{2}{*}{0.00} \\
\hline $\begin{array}{l}\text { Attended primary school 10th grade } \\
\text { High School: }\end{array}$ & & & \\
\hline Age at high school entry & 16.23 & $(0.60)$ & 0.01 \\
\hline Math track & 0.68 & & 0.04 \\
\hline High level Math & 0.28 & & 0.14 \\
\hline GPA & 8.29 & $(0.98)$ & -0.01 \\
\hline \multicolumn{4}{|l|}{ Highest completed education: } \\
\hline Length of education (years) & 15.35 & $(2.34)$ & 0.13 \\
\hline \multicolumn{4}{|l|}{ Educational level grouping: } \\
\hline Only high school & 0.17 & & -0.02 \\
\hline Vocational training & 0.10 & & 0.00 \\
\hline Short higher education (SHE) & 0.08 & & 0.00 \\
\hline Medium higher education (MHE) & 0.35 & & -0.01 \\
\hline Long higher education (LHE) & 0.28 & & 0.03 \\
\hline \multicolumn{4}{|l|}{ Educational level-subject grouping: } \\
\hline Only high school & 0.17 & & -0.02 \\
\hline Vocational training & 0.10 & & 0.00 \\
\hline SHE Technical & 0.02 & & 0.00 \\
\hline SHE Other & 0.06 & & 0.00 \\
\hline MHE Teacher & 0.09 & & 0.00 \\
\hline MHE Humanities & 0.05 & & 0.00 \\
\hline MHE Health & 0.08 & & 0.00 \\
\hline MHE SocSci & 0.05 & & 0.00 \\
\hline MHE TechSci & 0.06 & & 0.00 \\
\hline MHE Other & 0.02 & & 0.00 \\
\hline LHE Health & 0.03 & & 0.00 \\
\hline LHE NatSci & 0.04 & & 0.00 \\
\hline LHE Technical & 0.06 & & 0.01 \\
\hline LHE Humanities & 0.04 & & 0.00 \\
\hline LHE SocSci & 0.10 & & 0.02 \\
\hline LHE Other & 0.02 & & 0.00 \\
\hline \multicolumn{4}{|l|}{ Income: } \\
\hline Log Labor Income (real 2000 DKK) & 12.12 & $(0.96)$ & 0.04 \\
\hline \multicolumn{4}{|l|}{ Other individual variables: } \\
\hline Female & 0.56 & & -0.01 \\
\hline Labor Market Experience (years) & 4.81 & $(2.58)$ & -0.06 \\
\hline \multicolumn{4}{|l|}{$\begin{array}{l}\text { Parental background variables: } \\
\text { Income: }\end{array}$} \\
\hline Fathers' log income (real 2000 DKK) & 12.38 & $(0.55)$ & 0.03 \\
\hline Mothers' log income (real 2000 DKK) & 11.53 & $(1.07)$ & -0.04 \\
\hline \multicolumn{4}{|l|}{ Highest completed education: } \\
\hline Father basic school & 0.17 & & -0.01 \\
\hline Father high school & 0.02 & & 0.00 \\
\hline Father vocational training & 0.31 & & 0.01 \\
\hline Father short higher education & 0.03 & & 0.00 \\
\hline Father medium higher education & 0.18 & & 0.01 \\
\hline Father long higher education & 0.15 & & -0.01 \\
\hline Mother basic school & 0.23 & & -0.01 \\
\hline Mother high school & 0.02 & & -0.01 \\
\hline Mother vocational training & 0.33 & & 0.02 \\
\hline Mother short higher education & 0.05 & & 0.00 \\
\hline Mother medium higher education & 0.22 & & 0.00 \\
\hline Mother long higher education & 0.05 & & -0.01 \\
\hline Number of Individuals & & 543 & 255 \\
\hline
\end{tabular}

The table shows descriptive statistics for the estimation sample consisting of high school graduates from the 1986 and 1987 high school cohorts. For indicator variables the proportion of the sample included in the group is shown. For other variables the table provides the mean and the standard deviation (in parenthesis). The exchange rate on December 31, 2000 was 8.0205 DKK/USD. 
Table 2. Descriptive Statistics of Labor Market and Educational Outcomes.

\begin{tabular}{|c|c|c|c|c|c|c|}
\hline \multirow[b]{3}{*}{ Outcomes } & \multicolumn{6}{|c|}{ Sample means and (standard deviations) } \\
\hline & \multicolumn{2}{|c|}{ All } & \multicolumn{2}{|c|}{ PilotSchool $=0$} & \multicolumn{2}{|c|}{ PilotSchool $=1$} \\
\hline & $\begin{array}{c}\text { Overall } \\
\text { mean }\end{array}$ & $\begin{array}{c}\text { Mean } \\
\text { difference } \\
\text { by Math A }\end{array}$ & $\begin{array}{c}\text { Overall } \\
\text { mean }\end{array}$ & $\begin{array}{c}\text { Mean } \\
\text { difference } \\
\text { by Math A }\end{array}$ & $\begin{array}{c}\text { Overall } \\
\text { mean }\end{array}$ & $\begin{array}{c}\text { Mean } \\
\text { difference } \\
\text { by MathA }\end{array}$ \\
\hline Educational Outcomes: & & & & & & \\
\hline GPA in High School & $\begin{array}{c}8.29 \\
(0.97)\end{array}$ & 0.24 & $\begin{array}{c}8.30 \\
(0.98)\end{array}$ & 0.28 & $\begin{array}{c}8.29 \\
(0.98)\end{array}$ & 0.22 \\
\hline \multicolumn{7}{|l|}{ Sabbatical after High School: } \\
\hline Had Sabbatical & 0.82 & -0.11 & 0.79 & -0.18 & 0.84 & -0.11 \\
\hline Duration (years) of Sabbatical after High School & $\begin{array}{c}1.87 \\
(2.01)\end{array}$ & -0.66 & $\begin{array}{c}1.94 \\
(2.07)\end{array}$ & -0.71 & $\begin{array}{c}1.81 \\
(1.85)\end{array}$ & -0.61 \\
\hline \multicolumn{7}{|l|}{ First Higher Education Attempted: } \\
\hline Attempted Higher Education after High School & 0.87 & 0.06 & 0.86 & 0.06 & 0.87 & 0.05 \\
\hline Completed 1st Attempted Educ. Successfully & 0.62 & 0.08 & 0.62 & 0.09 & 0.63 & 0.08 \\
\hline \multicolumn{7}{|l|}{ Long Higher Educations: } \\
\hline Attempted Long Higher Education & 0.48 & 0.18 & 0.46 & 0.18 & 0.49 & 0.17 \\
\hline Completed Long Higher Education & 0.36 & 0.17 & 0.35 & 0.18 & 0.37 & 0.16 \\
\hline Years from High School Graduation until Completion & $\begin{array}{c}8.50 \\
(2.26)\end{array}$ & -1.00 & $\begin{array}{c}8.60 \\
(2.27)\end{array}$ & -1.01 & $\begin{array}{c}8.41 \\
(2.18)\end{array}$ & -0.98 \\
\hline Length of Highest Completed Education (years) & $\begin{array}{l}15.35 \\
(2.32)\end{array}$ & 0.79 & $\begin{array}{l}15.28 \\
(2.32)\end{array}$ & 0.85 & $\begin{array}{l}15.42 \\
(2.35)\end{array}$ & 0.74 \\
\hline \multicolumn{7}{|l|}{ Labor Market Outcomes: } \\
\hline Labor Income (real 2000 DKK) & $\begin{array}{l}12.12 \\
(0.94)\end{array}$ & 0.33 & $\begin{array}{l}12.10 \\
(0.95)\end{array}$ & 0.34 & $\begin{array}{l}12.13 \\
(0.89)\end{array}$ & 0.32 \\
\hline Degree of Unemployment (scale 0-1000) & $\begin{array}{c}35.66 \\
(114.23) \\
\end{array}$ & -15.61 & $\begin{array}{c}35.62 \\
(113.33) \\
\end{array}$ & -17.58 & $\begin{array}{c}35.71 \\
(106.10) \\
\end{array}$ & -14.85 \\
\hline Number of Individuals & 28543 & -12837 & 14144 & -8288 & 14399 & -4549 \\
\hline
\end{tabular}

The table shows descriptive statistics of labor market and educational outcomes after high school for the total estimation sample. A distinction between the two groups of high school graduates with high level Math and lower level Math, respectively, has been made. Within each Math level group, a distinction between the individuals attending PilotSchools and non-PilotSchools, respectively, has also been made. For indicator variables the proportion of the sample included in the group is shown. For other variables the table provides the mean and the standard deviation (in parenthesis). The exchange rate on December 31, 2000 was 8.0205 DKK/USD. 
Table 3. Estimation of the Effect of High Level Math on Labor Market Income for High School Graduates.

\begin{tabular}{|c|c|c|c|c|c|c|c|c|c|c|c|c|c|c|}
\hline & \multicolumn{14}{|c|}{ Parameter estimates, (standard errors) and [marginal effects] } \\
\hline & \multicolumn{7}{|c|}{ OLS } & \multicolumn{7}{|c|}{$\begin{array}{c}\text { IV } \\
\text { High School Mean Math } \\
\end{array}$} \\
\hline & $(1)$ & $(2)$ & $(3)$ & $(4)$ & $(5)$ & $(6)$ & $(7)$ & $\left(1^{\prime}\right)$ & $\left(2^{\prime}\right)$ & $\left(3^{\prime}\right)$ & $\left(4^{\prime}\right)$ & $\left(5^{\prime}\right)$ & $\left(6^{\prime}\right)$ & $\left(7^{\prime}\right)$ \\
\hline Outcome equation: & & & & & & & & & & & & & & \\
\hline High level Math & $\begin{array}{c}0.33 \\
(0.01)\end{array}$ & $\begin{array}{c}0.25 \\
(0.01)\end{array}$ & $\begin{array}{c}0.22 \\
(0.01)\end{array}$ & $\begin{array}{c}0.15 \\
(0.01)\end{array}$ & $\begin{array}{c}0.14 \\
(0.01)\end{array}$ & $\begin{array}{c}0.11 \\
(0.01)\end{array}$ & $\begin{array}{c}0.11 \\
(0.01)\end{array}$ & $\begin{array}{c}0.41 \\
(0.06)\end{array}$ & $\begin{array}{c}0.29 \\
(0.05)\end{array}$ & $\begin{array}{c}0.29 \\
(0.05)\end{array}$ & $\begin{array}{c}0.15 \\
(0.05)\end{array}$ & $\begin{array}{c}0.16 \\
(0.05)\end{array}$ & $\begin{array}{c}0.20 \\
(0.04)\end{array}$ & $\begin{array}{c}0.21 \\
(0.04)\end{array}$ \\
\hline First-Stage: & & & & & & & & & & & & & & \\
\hline High School Mean Math & & & & & & & & $\begin{array}{l}2.56 \\
(0.07) \\
{[0.84]}\end{array}$ & $\begin{array}{l}2.71 \\
(0.07) \\
{[0.86]}\end{array}$ & $\begin{array}{c}2.74 \\
(0.07) \\
{[0.86]}\end{array}$ & $\begin{array}{l}2.70 \\
(0.08) \\
{[0.85]}\end{array}$ & $\begin{array}{l}2.72 \\
(0.08) \\
{[0.85]}\end{array}$ & $\begin{array}{c}2.90 \\
(0.08) \\
{[0.89]}\end{array}$ & $\begin{array}{l}2.92 \\
(0.08) \\
{[0.89]}\end{array}$ \\
\hline $\begin{array}{l}\text { Additional control variables: } \\
\text { GPA } \\
\text { Individual variables: }\end{array}$ & & & + & & + & & + & & & + & & + & & + \\
\hline $\begin{array}{l}\text { Gender } \\
\text { Experience (quadratic) } \\
\text { Educational variables: }\end{array}$ & & $\begin{array}{l}+ \\
+\end{array}$ & $\begin{array}{l}+ \\
+\end{array}$ & $\begin{array}{l}+ \\
+\end{array}$ & $\begin{array}{l}+ \\
+\end{array}$ & $\begin{array}{l}+ \\
+\end{array}$ & $\begin{array}{l}+ \\
+\end{array}$ & & $\begin{array}{l}+ \\
+\end{array}$ & $\begin{array}{l}+ \\
+\end{array}$ & $\begin{array}{l}+ \\
+\end{array}$ & $\begin{array}{l}+ \\
+\end{array}$ & $\begin{array}{l}+ \\
+\end{array}$ & $\begin{array}{l}+ \\
+\end{array}$ \\
\hline $\begin{array}{l}\text { Educational level grouping } \\
\text { Educational level-subject grouping } \\
\text { Parental variables (for mother and father): }\end{array}$ & & & & + & + & + & + & & & & + & + & + & + \\
\hline Highest completed education, and income & & + & + & + & + & + & + & & + & + & + & + & + & + \\
\hline
\end{tabular}

The table shows estimates of the effect of high level Math on labor market income thirteen years after starting high school. The two different estimation strategies are: Ordinary Least Squares (OLS) on the total sample of high school graduates who start high school in 1986 or 1987, and Instrumental Variables (IV) estimation using Altonji's instrument, the mean participation rate in the high level Math course in own high school year group as an instrument for Math qualifications. There are seven distinct specifications for each estimation strategy, corresponding to the columns (1)-(7). They differ by the explanatory variables included, and + (plus) indicates which sets of explanatory variables are included in the estimation. The dependent variable is log labor market income thirteen years after starting high school. The top row provides the parameter estimates of the effect of MathA on log labor market income and the standard errors (in parentheses). The bottom row provides the parameter estimates regarding the instrument in the first-stage Math $A$ selection equation, the standard errors (in parentheses), and marginal effects [in square brackets]. Bold indicates that the parameter is significant at the $1 \%$ level of significance. 
Table 4. Estimation of the Causal Effect of High Level Math on Labor Market Income for High School Graduates.

\begin{tabular}{|c|c|c|c|c|c|c|c|c|c|c|c|c|c|c|}
\hline & \multicolumn{14}{|c|}{ Parameter estimates, (standard errors) and [marginal effects] } \\
\hline & \multicolumn{7}{|c|}{$\begin{array}{c}\text { IV } \\
\text { Pilot School }\end{array}$} & \multicolumn{7}{|c|}{$\begin{array}{c}\text { IV } \\
\text { Dist Pilot School }(10 \mathrm{~km})\end{array}$} \\
\hline & $(1)$ & $(2)$ & $(3)$ & $(4)$ & $(5)$ & (6) & (7) & $\left(1^{\prime}\right)$ & $\left(2^{\prime}\right)$ & $\left(3^{\prime}\right)$ & $\left(4^{\prime}\right)$ & $\left(5^{\prime}\right)$ & $\left(6^{\prime}\right)$ & $\left(7^{\prime}\right)$ \\
\hline Outcome equation: & & & & & & & & & & & & & & \\
\hline High level Math & $\begin{array}{c}0.26 \\
(0.08)\end{array}$ & $\begin{array}{c}0.29 \\
(0.07)\end{array}$ & $\begin{array}{c}0.32 \\
(0.06)\end{array}$ & $\begin{array}{c}0.12 \\
(0.06)\end{array}$ & $\begin{array}{c}0.13 \\
(0.06)\end{array}$ & $\begin{array}{c}0.20 \\
(0.06)\end{array}$ & $\begin{array}{c}0.21 \\
(0.06)\end{array}$ & $\begin{array}{c}0.32 \\
(0.22)\end{array}$ & $\begin{array}{c}0.47 \\
(0.14)\end{array}$ & $\begin{array}{c}0.51 \\
(0.13)\end{array}$ & $\begin{array}{c}0.19 \\
(0.12)\end{array}$ & $\begin{array}{c}0.21 \\
(0.12)\end{array}$ & $\begin{array}{c}0.47 \\
(0.11)\end{array}$ & $\begin{array}{c}0.47 \\
(0.11)\end{array}$ \\
\hline First-Stage: & & & & & & & & & & & & & & \\
\hline IV (PilotSchool or DistPilotSchool) & $\begin{array}{l}0.41 \\
(0.02) \\
{[0.14]}\end{array}$ & $\begin{array}{l}0.44 \\
(0.02) \\
{[0.14]}\end{array}$ & $\begin{array}{l}0.45 \\
(0.02) \\
{[0.14]}\end{array}$ & $\begin{array}{l}0.44 \\
(0.02) \\
{[0.14]}\end{array}$ & $\begin{array}{l}0.44 \\
(0.02) \\
{[0.14]}\end{array}$ & $\begin{array}{l}0.48 \\
(0.02) \\
{[0.15]}\end{array}$ & $\begin{array}{l}0.48 \\
(0.02) \\
{[0.15]}\end{array}$ & $\begin{array}{l}-0.11 \\
(0.01) \\
{[-0.03]}\end{array}$ & $\begin{array}{l}-0.11 \\
(0.01) \\
{[-0.03]}\end{array}$ & $\begin{array}{l}-0.11 \\
(0.01) \\
{[-0.03]}\end{array}$ & $\begin{array}{l}-0.11 \\
(0.01) \\
{[-0.03]}\end{array}$ & $\begin{array}{l}-0.11 \\
(0.01) \\
{[-0.03]}\end{array}$ & $\begin{array}{l}-0.12 \\
(0.01) \\
{[-0.04]}\end{array}$ & $\begin{array}{l}-0.12 \\
(0.01) \\
{[-0.04]}\end{array}$ \\
\hline $\begin{array}{l}\text { Additional control variables: } \\
\text { GPA } \\
\text { Individual variables: }\end{array}$ & & & + & & + & & + & & & + & & + & & + \\
\hline $\begin{array}{l}\text { Gender } \\
\text { Experience (quadratic) } \\
\text { Educational variables: }\end{array}$ & & $\begin{array}{l}+ \\
+\end{array}$ & $\begin{array}{l}+ \\
+\end{array}$ & $\begin{array}{l}+ \\
+\end{array}$ & $\begin{array}{l}+ \\
+\end{array}$ & $\begin{array}{l}+ \\
+\end{array}$ & $\begin{array}{l}+ \\
+\end{array}$ & & $\begin{array}{l}+ \\
+\end{array}$ & $\begin{array}{l}+ \\
+\end{array}$ & $\begin{array}{l}+ \\
+\end{array}$ & $\begin{array}{l}+ \\
+\end{array}$ & $\begin{array}{l}+ \\
+\end{array}$ & $\begin{array}{l}+ \\
+\end{array}$ \\
\hline $\begin{array}{l}\text { Educational level grouping } \\
\text { Educational level-subject grouping } \\
\text { Parental variables (for mother and father): }\end{array}$ & & & & + & + & + & + & & & & + & + & + & + \\
\hline Highest completed education, and income & & + & + & + & + & + & + & & + & + & + & + & + & + \\
\hline
\end{tabular}

The table shows estimates of the effect of high level Math on labor market income thirteen years after starting high school. The two different estimation strategies are: Instrumental Variables (IV) estimation using an indicator for starting high school with the option of choosing high level Math on a try out experimental curricula, PilotSchool, as an instrument for Math qualifications, and IV using the difference between the distance to the nearest high school with an experimental curricula and the nearest high school, DistPilotSchool, as an instrument for Math qualifications. There are seven distinct specifications for each estimation strategy, corresponding to the columns (1)-(7). They differ by the explanatory variables included, and + (plus) indicates which sets of explanatory variables are strategy, corresponding to the columns (1)-(7). They differ by the explanatory variables included, and + (plus) indicates which sets of explanatory variables are
included in the estimation. The dependent variable is log labor market income thirteen years after starting high school. The top row provides the parameter estimates of the causal effect of Math $A$ on log labor market income and the standard errors (in parentheses). The bottom row provides the parameter estimates regarding the instrument in the first-stage $M a t h A$ selection equation, the standard errors (in parentheses), and marginal effects [in square brackets]. Bold indicates that the parameter is significant at the $1 \%$ level of significance. 
Table 5. Descriptive Statistics of High School Proximity and Choices.

\begin{tabular}{|c|c|c|c|c|c|c|c|c|c|}
\hline \multirow[b]{3}{*}{ Variable } & \multicolumn{9}{|c|}{ Means and (standard deviations) } \\
\hline & \multicolumn{3}{|c|}{ All } & \multicolumn{3}{|c|}{ Rural } & \multicolumn{3}{|c|}{ Urban } \\
\hline & Overa & 11 mean & $\begin{array}{c}\text { Mean } \\
\text { difference by } \\
\text { PilotSchool } \\
\end{array}$ & Over & 11 mean & $\begin{array}{c}\text { Mean } \\
\text { difference by } \\
\text { PilotSchool } \\
\end{array}$ & Overa & 11 mean & $\begin{array}{c}\text { Mean } \\
\text { difference by } \\
\text { PilotSchool } \\
\end{array}$ \\
\hline Pilot School & 0.50 & & 1.00 & 0.53 & & 1.00 & 0.45 & & 1.00 \\
\hline Dist Pilot School $(10 \mathrm{~km})$ & 0.50 & $(1.00)$ & -0.90 & 0.66 & $(1.18)$ & -1.30 & 0.19 & $(0.32)$ & -0.24 \\
\hline \multicolumn{10}{|l|}{ Shortest road distance $(10 \mathrm{~km})$ to: } \\
\hline Nearest Pilot High School & 1.17 & $(1.20)$ & -0.86 & 1.47 & $(1.33)$ & -1.36 & 0.56 & $(0.49)$ & -0.13 \\
\hline Actually chosen High School & 0.94 & $(1.43)$ & -0.02 & 1.07 & $(1.57)$ & -0.07 & 0.68 & $(1.07)$ & 0.01 \\
\hline \multicolumn{10}{|l|}{ Actual Choice of High School: } \\
\hline Nearest High School & 0.66 & & 0.12 & 0.75 & & 0.03 & 0.47 & & 0.22 \\
\hline Nearest Pilot High School & 0.41 & & 0.81 & 0.47 & & 0.87 & 0.31 & & 0.67 \\
\hline Nearest High School and Pilot School & 0.36 & & 0.71 & 0.41 & & 0.76 & 0.27 & & 0.59 \\
\hline Travel distance excess of nearest High School & 0.28 & $(1.23)$ & -0.06 & 0.27 & $(1.35)$ & -0.03 & 0.30 & $(0.95)$ & -0.11 \\
\hline Number of Individuals & & 543 & 255 & & 967 & 1227 & & 576 & -972 \\
\hline
\end{tabular}

The table shows descriptive statistics of high school distances and choices for the total estimation sample. A distinction between the two groups of high schools in the rural and urban areas, respectively, has been made. The urban area includes the four biggest cities: Copenhagen, Aarhus, Odense and Aalborg. Within each geographical group, a distinction between the individuals attending PilotSchools and non-PilotSchools, respectively, has also been made. For indicator variables the proportion of the sample included in the group is shown. For distance measures the table provides the mean and the standard deviation (in parenthesis). 
Table 6. Sensitivity Analysis of the Estimates of the Causal Effect of High Level Math on Labor Market Income.

\begin{tabular}{|c|c|c|c|c|c|c|c|c|c|}
\hline & \multicolumn{9}{|c|}{ Parameter estimates, (standard errors) and [marginal effects] } \\
\hline & \multicolumn{3}{|c|}{$\begin{array}{c}\text { IV } \\
\text { Pilot School }\end{array}$} & \multicolumn{3}{|c|}{$\begin{array}{c}\text { IV } \\
\text { DistPilotSchool }(10 \mathrm{~km})\end{array}$} & \multicolumn{3}{|c|}{$\begin{array}{c}\text { IV } \\
P S * \text { DistPS }(10 \mathrm{~km})\end{array}$} \\
\hline & $(1)$ & $(2)$ & $(4)$ & $\left(1^{\prime}\right)$ & $\left(2^{\prime}\right)$ & $\left(4^{\prime}\right)$ & $(1 ")$ & $(2 " \prime)$ & $(4 ")$ \\
\hline \multicolumn{10}{|l|}{ Outcome equation: } \\
\hline High level Math & $\begin{array}{c}0.26 \\
(0.08)\end{array}$ & $\begin{array}{c}0.29 \\
(0.07)\end{array}$ & $\begin{array}{c}0.12 \\
(0.06)\end{array}$ & $\begin{array}{c}0.32 \\
(0.22)\end{array}$ & $\begin{array}{c}0.47 \\
(0.14)\end{array}$ & $\begin{array}{c}0.19 \\
(0.12)\end{array}$ & & & \\
\hline \multicolumn{10}{|l|}{ First-Stage: } \\
\hline IV (PilotSchool or DistPilotSchool) & $\begin{array}{c}0.41 \\
(0.02) \\
{[0.14]}\end{array}$ & $\begin{array}{c}0.44 \\
(0.02) \\
{[0.14]}\end{array}$ & $\begin{array}{c}0.44 \\
(0.02) \\
{[0.14]}\end{array}$ & $\begin{array}{c}-0.11 \\
(0.01) \\
{[-0.03]}\end{array}$ & $\begin{array}{c}-0.11 \\
(0.01) \\
{[-0.03]}\end{array}$ & $\begin{array}{c}-0.11 \\
(0.01) \\
{[-0.03]}\end{array}$ & & & \\
\hline \multicolumn{10}{|l|}{ Outcome equation: } \\
\hline High level Math & $\begin{array}{c}0.22 \\
(0.09)\end{array}$ & $\begin{array}{c}0.24 \\
(0.07)\end{array}$ & $\begin{array}{l}0.05 \\
(0.07)\end{array}$ & $\begin{array}{c}0.03 \\
(0.37)\end{array}$ & $\begin{array}{c}0.21 \\
(0.14)\end{array}$ & $\begin{array}{l}-0.02 \\
(0.12)\end{array}$ & $\begin{array}{c}0.51 \\
(0.38)\end{array}$ & $\begin{array}{c}0.31 \\
(0.14)\end{array}$ & $\begin{array}{c}0.06 \\
(0.12)\end{array}$ \\
\hline \multicolumn{10}{|l|}{ First-Stage: } \\
\hline IV (PilotSchool, DistPilotSchool or PS*DistPS) & $\begin{array}{c}0.43 \\
(0.02) \\
{[0.14]}\end{array}$ & $\begin{array}{c}0.47 \\
(0.02) \\
{[0.15]}\end{array}$ & $\begin{array}{c}0.47 \\
(0.02) \\
{[0.15]}\end{array}$ & $\begin{array}{c}0.02 \\
(0.01) \\
{[0.01]}\end{array}$ & $\begin{array}{c}0.03 \\
(0.01) \\
{[0.01]}\end{array}$ & $\begin{array}{c}0.03 \\
(0.01) \\
{[0.01]}\end{array}$ & $\begin{array}{c}-0.06 \\
(0.04) \\
{[-0.02]}\end{array}$ & $\begin{array}{c}-0.06 \\
(0.04) \\
{[-0.02]}\end{array}$ & $\begin{array}{c}-0.05 \\
(0.04) \\
{[-0.02]}\end{array}$ \\
\hline \multicolumn{10}{|l|}{ Additional control variables: } \\
\hline DistPilotSchool & + & + & + & + & + & & $\begin{array}{l}+ \\
+\end{array}$ & $\begin{array}{l}+ \\
+\end{array}$ & $\begin{array}{l}+ \\
+\end{array}$ \\
\hline GPA & & + & + & & + & + & & + & + \\
\hline Gender & & + & + & & + & + & & + & + \\
\hline Experience (quadratic) & & + & + & & + & + & & + & + \\
\hline Educational level grouping & & & + & & & + & & & + \\
\hline Parents' highest completed education and income & & + & + & & + & + & & + & + \\
\hline
\end{tabular}

The table shows sensitivity analysis of the estimates of the effect of high level Math on labor market income thirteen years after starting high school. The three different estimation strategies are: IV using an indicator for starting high school with the option of choosing high level Math on an experimental curricula, PilotSchool, as an instrument, IV using the difference between the shortest road distance to the nearest high school with an experimental curricula and the nearest high school, DistPilotSchool, as an instrument, and IV using the interaction term PilotSchool*DistPilotSchool as an instrument for Math qualifications. There are three distinct specifications for each estimation strategy, corresponding to the columns (1), (2) and (4) in Tables 3 and 4 . They differ by the explanatory variables included, and + (plus) indicates which sets of explanatory variables are included in the estimation. The dependent variable is log labor market income thirteen years after starting high school. The upper panel redisplays the estimation results from Table 4 as a point of reference, and the lower panel shows the estimates from the corresponding specifications including the alternative instrument as a control variable. In each panel, the top row provides the parameter estimates of the causal effect of $M a t h A$ on log labor market income and the standard errors (in parentheses), and the bottom row provides the parameter estimates regarding the instrument in the first-stage $M a t h A$ selection equation, the standard errors (in parentheses), and marginal effects [in square brackets]. Bold indicates that the parameter is significant at the $1 \%$ level of significance. 
Table A1. Sensitivity Analysis of IV Estimates of the Effect of high level Math on Labor Market Income, PilotSchool.

\begin{tabular}{|c|c|c|c|c|c|c|c|}
\hline & \multicolumn{7}{|c|}{ Parameter estimates and (standard errors) } \\
\hline & \multicolumn{7}{|c|}{$\begin{array}{c}\text { IV } \\
\text { Pilot School }\end{array}$} \\
\hline & $(1)$ & $(2)$ & $(3)$ & $(4)$ & $(5)$ & $(6)$ & $(7)$ \\
\hline Outcome equation: & & & & & & & \\
\hline High level Math & $\begin{array}{c}0.26 \\
(0.08)\end{array}$ & $\begin{array}{c}0.29 \\
(0.07)\end{array}$ & $\begin{array}{c}0.32 \\
(0.06)\end{array}$ & $\begin{array}{c}0.12 \\
(0.06)\end{array}$ & $\begin{array}{c}0.13 \\
(0.06)\end{array}$ & $\begin{array}{c}0.20 \\
(0.06)\end{array}$ & $\begin{array}{c}0.21 \\
(0.06)\end{array}$ \\
\hline Conventional IV (2SLS) & $\begin{array}{c}0.27 \\
(0.08)\end{array}$ & $\begin{array}{c}0.30 \\
(0.08)\end{array}$ & $\begin{array}{c}0.32 \\
(0.07)\end{array}$ & $\begin{array}{c}0.16 \\
(0.07)\end{array}$ & $\begin{array}{c}0.17 \\
(0.07)\end{array}$ & $\begin{array}{c}0.15 \\
(0.07)\end{array}$ & $\begin{array}{c}0.16 \\
(0.07)\end{array}$ \\
\hline IV Method 1 & $\begin{array}{c}0.27 \\
(0.08)\end{array}$ & $\begin{array}{c}0.29 \\
(0.07)\end{array}$ & $\begin{array}{c}0.29 \\
(0.07)\end{array}$ & $\begin{array}{c}0.07 \\
(0.07)\end{array}$ & $\begin{array}{c}0.07 \\
(0.07)\end{array}$ & $\begin{array}{c}0.15 \\
(0.07)\end{array}$ & $\begin{array}{c}0.16 \\
(0.07)\end{array}$ \\
\hline IV Method 2 & $\begin{array}{c}0.27 \\
(0.08)\end{array}$ & $\begin{array}{c}0.52 \\
(0.18)\end{array}$ & $\begin{array}{c}0.52 \\
(0.17)\end{array}$ & $\begin{array}{c}0.25 \\
(0.13)\end{array}$ & $\begin{array}{c}0.22 \\
(0.13)\end{array}$ & $\begin{array}{c}0.11 \\
(0.10)\end{array}$ & $\begin{array}{c}0.11 \\
(0.10)\end{array}$ \\
\hline IV Method 3 & $\begin{array}{c}0.23 \\
(0.09)\end{array}$ & $\begin{array}{c}0.23 \\
(0.08)\end{array}$ & $\begin{array}{c}0.28 \\
(0.08)\end{array}$ & $\begin{array}{c}0.16 \\
(0.08)\end{array}$ & $\begin{array}{c}0.18 \\
(0.08)\end{array}$ & $\begin{array}{c}0.17 \\
(0.08)\end{array}$ & $\begin{array}{c}0.19 \\
(0.08)\end{array}$ \\
\hline IV Method 4 & $\begin{array}{c}0.26 \\
(0.08)\end{array}$ & $\begin{array}{c}0.28 \\
(0.07)\end{array}$ & $\begin{array}{c}0.31 \\
(0.06)\end{array}$ & $\begin{array}{c}0.12 \\
(0.06)\end{array}$ & $\begin{array}{c}0.14 \\
(0.06)\end{array}$ & $\begin{array}{c}0.19 \\
(0.06)\end{array}$ & $\begin{array}{c}0.20 \\
(0.06)\end{array}$ \\
\hline $\begin{array}{l}\text { First-Stage: } \\
\text { Pilot School }\end{array}$ & $\begin{array}{l}{[0.14]} \\
(0.01)\end{array}$ & $\begin{array}{l}{[0.13]} \\
(0.01)\end{array}$ & $\begin{array}{l}{[0.13]} \\
(0.01)\end{array}$ & $\begin{array}{l}{[0.13]} \\
(0.01)\end{array}$ & $\begin{array}{l}{[0.13]} \\
(0.01)\end{array}$ & $\begin{array}{l}{[0.13]} \\
(0.01)\end{array}$ & $\begin{array}{l}{[0.13]} \\
(0.01)\end{array}$ \\
\hline Conventional IV (2SLS) & $\begin{array}{c}0.14 \\
(0.01)\end{array}$ & $\begin{array}{c}0.13 \\
(0.00)\end{array}$ & $\begin{array}{c}0.13 \\
(0.00)\end{array}$ & $\begin{array}{c}0.13 \\
(0.00)\end{array}$ & $\begin{array}{c}0.13 \\
(0.00)\end{array}$ & $\begin{array}{c}0.13 \\
(0.00)\end{array}$ & $\begin{array}{c}0.13 \\
(0.00)\end{array}$ \\
\hline Additional control variables: & & & & & & & \\
\hline $\begin{array}{l}\text { GPA } \\
\text { Individual variables: }\end{array}$ & & & + & & + & & + \\
\hline Gender & & + & + & + & + & + & + \\
\hline $\begin{array}{l}\text { Experience (quadratic) } \\
\text { Educational variables: }\end{array}$ & & + & + & + & + & + & + \\
\hline Educational level grouping & & & & + & + & & \\
\hline $\begin{array}{l}\text { Educational level-subject grouping } \\
\text { Parental variables (for mother and father): }\end{array}$ & & & & & & + & + \\
\hline Highest completed education, and income & & + & + & + & + & + & + \\
\hline
\end{tabular}

The table shows estimates of the effect of high level Math on labor market income thirteen years after starting high school. The instrument is an indicator for attending a high school with an experimental curricula offering high level Math, PilotSchool. The five different IV estimation methods are: Conventional IV (2SLS) $\left(\right.$ Math $_{i}$ instrumented by PilotSchool ${ }_{i}$ ), IV Method 1 (MathA $A_{i}$ instrumented by the first step probit choice probability $\Phi(\cdot))$, IV Method $2\left(\right.$ Math $A_{i}$ instrumented by the first step probit choice probability $\Phi(\cdot)$, furthermore interaction terms $\operatorname{Math} A_{i}\left(x_{i}-\bar{x}\right)$ are allowed for, and instrumented by $\Phi(\cdot)\left(x_{i}-\bar{x}\right)$ ), and at last $\phi(\cdot)$ is also included), IV Method 3 (most general version of the IV method we have applied previously, here the outcome equation is augmented by the interaction terms $\operatorname{Math}_{i}\left(X_{i^{-}}\right.$ $\bar{x}), \operatorname{Math} A_{i} \cdot \gamma_{1 i}$, (1-Math $\left.A_{i}\right) \cdot \gamma_{o i}$ and estimated by OLS, and finally IV Method 4 is a slightly more general version of the IV method we have applied previously, here the outcome equation is augmented by the interaction terms $\operatorname{Math}_{i} \cdot \gamma_{1 i}$ and $\left(1-\operatorname{Math} A_{i}\right) \cdot \gamma_{o i}$, and estimated by OLS). In the first rows the IV estimates from the estimation described in Section 4 are redisplayed for comparison (here the outcome equation is augmented by the the hazard $\gamma_{i}=\operatorname{Math} A_{i} \cdot \gamma_{1 i}+\left(1-\operatorname{Math} A_{i}\right) \cdot \gamma_{o i}$ and estimated by OLS). All IV estimations are conducted on the sample of high school graduates who start high school in 1987. There are seven distinct specifications for each estimation strategy, corresponding to the columns (1)-(7). They differ by the explanatory variables included, and + (plus) indicates which sets of explanatory variables are included in the estimation. The dependent variable is log labor market income thirteen years after starting high school. The first row provides the parameter estimates and the second row the standard errors (in parentheses). Bold indicates that the parameter is significant at the $1 \%$ level of significance. 
Table B1. Estimation of the Implied Bias in the Conventional IV Coefficients.

\begin{tabular}{|c|c|c|c|c|c|c|c|}
\hline & \multicolumn{7}{|c|}{ Parameter estimates and (standard errors) } \\
\hline & \multicolumn{7}{|c|}{$\begin{array}{c}\text { IV } \\
\text { Pilot School } \\
\end{array}$} \\
\hline & $(1)$ & $(2)$ & $(3)$ & $(4)$ & $(5)$ & $(6)$ & $(7)$ \\
\hline \multicolumn{8}{|l|}{$\begin{array}{l}\text { Outcome equation: } \\
\text { High level Math }\end{array}$} \\
\hline Conventional IV (2SLS) coefficient & $\begin{array}{c}0.27 \\
(0.08)\end{array}$ & $\begin{array}{c}0.30 \\
(0.08)\end{array}$ & $\begin{array}{c}0.32 \\
(0.07)\end{array}$ & $\begin{array}{c}0.16 \\
(0.07)\end{array}$ & $\begin{array}{c}0.17 \\
(0.07)\end{array}$ & $\begin{array}{c}0.15 \\
(0.07)\end{array}$ & $\begin{array}{c}0.16 \\
(0.07)\end{array}$ \\
\hline Implied bias in IV coefficient & $\begin{array}{c}0.06 \\
(0.16)\end{array}$ & $\begin{array}{c}0.21 \\
(0.16)\end{array}$ & $\begin{array}{c}0.22 \\
(0.16)\end{array}$ & $\begin{array}{c}0.10 \\
(0.16)\end{array}$ & $\begin{array}{c}0.11 \\
(0.15)\end{array}$ & $\begin{array}{c}0.10 \\
(0.16)\end{array}$ & $\begin{array}{c}0.11 \\
(0.15)\end{array}$ \\
\hline \multicolumn{8}{|l|}{ Additional control variables: } \\
\hline $\begin{array}{l}\text { GPA } \\
\text { Individual variables: }\end{array}$ & & & + & & + & & + \\
\hline Gender & & + & + & + & + & + & + \\
\hline $\begin{array}{l}\text { Experience (quadratic) } \\
\text { Educational variables: }\end{array}$ & & + & + & + & + & + & + \\
\hline Educational level grouping & & & & + & + & & \\
\hline $\begin{array}{l}\text { Educational level-subject grouping } \\
\text { Parental variables (for mother and father): }\end{array}$ & & & & & & + & + \\
\hline Highest completed education, and income & & + & + & + & + & + & + \\
\hline
\end{tabular}

The first row of the table redisplays the Conventional IV (2SLS) estimates of the causal effect of high level Math for the experimental curricula instrument, PilotSchool, on labor market income thirteen years after starting high school. The second row of the table shows the estimated biases in the corresponding IV coefficients in the first row of the table. The columns represent the seven distinct specifications (1)-(7) that differ by the explanatory variables included. + (plus) indicates which sets of explanatory variables are included in the estimation. The dependent variable is labor market income thirteen years after starting high school. Each row provides the parameter estimates and the standard errors (in parentheses). Bold indicates that the parameter is significant at the $5 \%$ level of significance. 
Figure 1. Overview of the Content of Math Courses.

\begin{tabular}{lccc}
\hline & $\begin{array}{c}\text { High level } \\
\text { Math }\end{array}$ & $\begin{array}{c}\text { Medium level } \\
\text { Math }\end{array}$ & $\begin{array}{c}\text { Low level } \\
\text { Math }\end{array}$ \\
\hline Core subjects & & & \\
(1) Theory of Sets and Algebra & + & + & \\
(2) Number Theory & + & + & + \\
(3) Combinatorics and Probability Theory & + & + & + \\
(4) Equations and Inequalities & + & + & + \\
(5) Plane Geometry & + & & \\
(6) Solid Geometry & + & + & \\
(7) Elementary Functions & + & + & \\
(8) Infinitesimal Calculus & + & + & \\
(9) Applications of infinitesimal calculus. & + & & \\
(10) Optional topic & + & & \\
& & & \\
Hours per week & 5 & 5 & \\
$1^{\text {st }}$ year & 6 & 4 & \\
$2^{\text {nd }}$ year & 6 & 3 & \\
$3^{\text {rd }}$ year & & & \\
\hline
\end{tabular}

Note: The figure presents the contents of the Math courses and the number of lecture hours per week. 
Figure 2. Overview of the Branch-based High School.
$1^{\text {st }}$ year
$2^{\text {nd }}$ and $3^{\text {rd }}$ year

\begin{tabular}{|l|}
\hline Math track \\
Courses taught at both tracks: \\
High level: \\
Danish \\
History \\
Medium level: \\
French or Russian \\
Low level: \\
Ancient history \\
Sports \\
Religion \\
Music or Visual arts \\
Mandatory courses taught at \\
the Math track only: \\
Math \\
Physics \\
Chemistry \\
English/German \\
\end{tabular}

\section{Math - Social Science}

Medium level Math, high level Social Science, medium level Physics and Geography, low level Chemistry and Biology.

Math - Natural Science

Medium level Math, high level Biology, medium level Physics, Chemistry and Geographv.

\section{Math - Music}

Medium level Math, high level Music, medium level Physics and Geography, low level Chemistry and Biology.

\section{Math - Physics}

High level Math, high level Physics, medium level Chemistry, low level Biology and Geography.

Math - Chemistry

High level Math, high level Chemistry, medium level Physics, low level Biology and

Geography.

\section{Language track}

Courses taught at both tracks:

High level:

Danish

History

Medium level:

French or Russian

Low level:

Ancient history

Sports

Religion

Music or Visual arts

Mandatory courses taught at the Language track only:

English

German

Latin

Biology

Geography

\section{Social Science and languages}

High level Social Science, high level English or German and medium level

Geography.

Music and languages

High level Music, high level English or German and medium level Latin.

\section{Modern languages}

High level English and German,, and medium level Latin.

\section{Classical languages}

High level Latin along with high level Greek or Ancient History. 
Figure 3a. Distribution of Branch Choices, by PilotSchool.

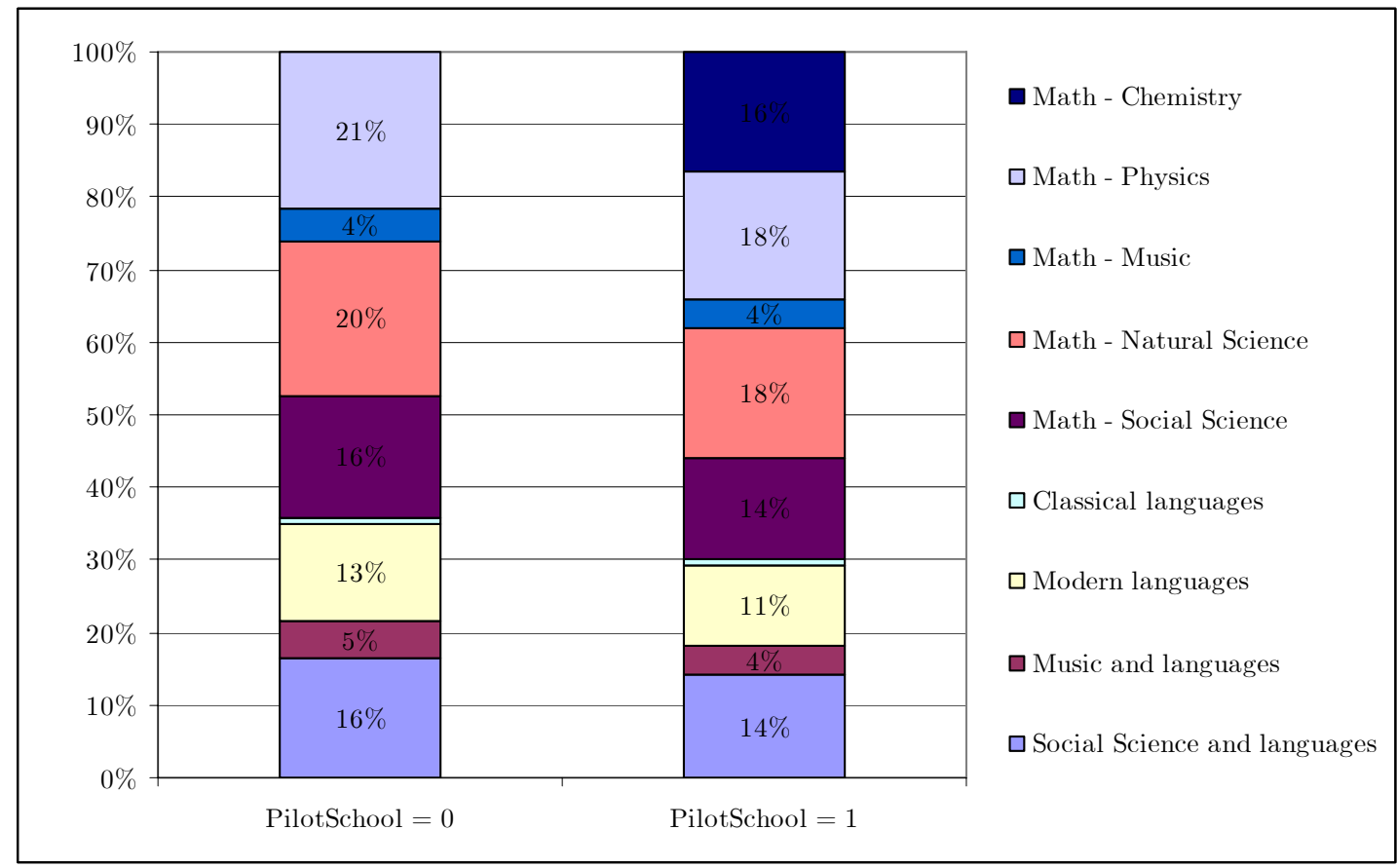

Figure 3b. Advanced Course Choices, by PilotSchool.

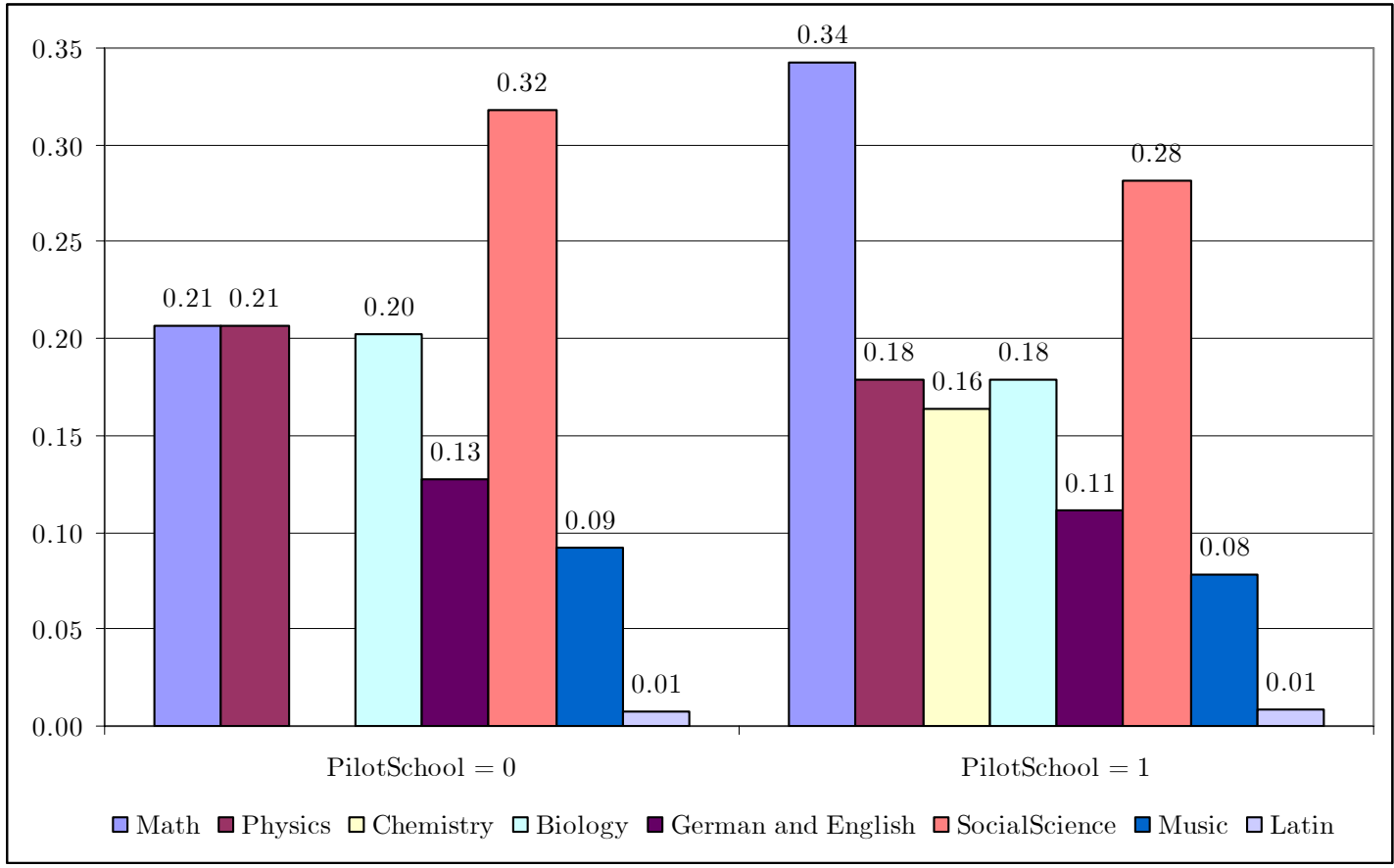

